OPEN ACCESS

Edited by:

Sebastian Dworkin

La Trobe University, Australia

Reviewed by:

Guang Wang,

Jinan University, China

Regie Santos-Cortez,

University of Colorado, United States

${ }^{*}$ Correspondence:

Paul A. Trainor

pat@stowers.org

Specialty section:

This article was submitted to

Molecular Medicine

a section of the journal

Frontiers in Cell and Developmental

Biology

Received: 21 December 2020 Accepted: 21 April 2021

Published: 20 May 2021

Citation:

Fitriasari S and Trainor PA (2021) Diabetes, Oxidative Stress, and DNA

Damage Modulate Cranial Neural Crest Cell Development and the Phenotype Variability

of Craniofacial Disorders.

Front. Cell Dev. Biol. 9:644410. doi: 10.3389/fcell.2021.644410

\section{Diabetes, Oxidative Stress, and DNA Damage Modulate Cranial Neural Crest Cell Development and the Phenotype Variability of Craniofacial Disorders}

\author{
Sharien Fitriasari ${ }^{1}$ and Paul A. Trainor, ${ }^{1,2 *}$ \\ 'Stowers Institute for Medical Research, Kansas City, MO, United States, ${ }^{2}$ Department of Anatomy and Cell Biology, \\ University of Kansas Medical Center, Kansas City, KS, United States
}

Craniofacial malformations are among the most common birth defects in humans and they often have significant detrimental functional, aesthetic, and social consequences. To date, more than 700 distinct craniofacial disorders have been described. However, the genetic, environmental, and developmental origins of most of these conditions remain to be determined. This gap in our knowledge is hampered in part by the tremendous phenotypic diversity evident in craniofacial syndromes but is also due to our limited understanding of the signals and mechanisms governing normal craniofacial development and variation. The principles of Mendelian inheritance have uncovered the etiology of relatively few complex craniofacial traits and consequently, the variability of craniofacial syndromes and phenotypes both within families and between families is often attributed to variable gene expression and incomplete penetrance. However, it is becoming increasingly apparent that phenotypic variation is often the result of combinatorial genetic and non-genetic factors. Major non-genetic factors include environmental effectors such as pregestational maternal diabetes, which is well-known to increase the risk of craniofacial birth defects. The hyperglycemia characteristic of diabetes causes oxidative stress which in turn can result in genotoxic stress, DNA damage, metabolic alterations, and subsequently perturbed embryogenesis. In this review we explore the importance of gene-environment associations involving diabetes, oxidative stress, and DNA damage during cranial neural crest cell development, which may underpin the phenotypic variability observed in specific craniofacial syndromes.

Keywords: diabetes, ROS, DNA damage, neural crest cell, craniofacial development

\section{INTRODUCTION}

The vertebrate head and face comprise a complex assemblage of specialized tissues including the viscerocranium, chondrocranium and neurocranium, the central and peripheral nervous systems, and all of the major sense organs (Trainor, 2013). The anatomical complexity of the craniofacial complex coupled with the initiation of its development during early embryogenesis renders the head and face prone to malformation. In fact, of the $1 \%$ of all live births that present with a 
minor or major anomaly, about one-third affect the head and face (Gorlin et al., 1990). To date, more than 700 distinct craniofacial disorders have been identified and phenotypically described (Carey, 1992), and orofacial clefts $(1: 1,000)$ and craniosynostosis $(1: 2,500)$ represent two of the most common craniofacial birth defects. These disorders are characterized by a wide spectrum of anomalies with varying degrees of severity, and no phenotypes or syndromes are identical in all affected individuals. In fact, many affected individuals with extremely mild phenotypes go undiagnosed or are only diagnosed retrospectively upon the birth of a severely affected sibling or progeny (Trainor et al., 2009). Additionally, craniofacial anomalies can occur sporadically without a familial history of mutation, indicating that genetic background, environmental factors, and stochastic events can influence the etiology and pathogenesis of craniofacial disorders (Jones et al., 1975; Trainor et al., 2009; Bartzela et al., 2017). Therefore, a thorough understanding of the events controlling normal craniofacial morphogenesis is central to improving diagnosis and care for patients.

Craniofacial malformations typically arise due to defects in cranial neural crest cell formation, migration, or differentiation and are collectively termed "neurocristopathies." Distinct and diverse phenotypes manifest depending on which phase of cNCC development is disrupted (Trainor, 2010; Watt and Trainor, 2014). Although variable gene expression and incomplete penetrance contribute to phenotypic variability, the impact of combinatorial genetic and non-genetic factors in craniofacial malformations is increasingly being recognized. A growing body of evidence demonstrates that neural crest cells are particularly sensitive to environmental influences such as diabetes and oxidative stress. Maternal diabetes is associated with an increased risk of birth defects (Kucera, 1971; Casson et al., 1997; Hawthorne et al., 1997; Von Kries et al., 1997; Mills, 2010) and may account for half of all perinatal deaths (Greene, 2001). In fact, women with pre-gestational diabetes have children with birth defects three to five times more frequently than women without diabetes (Greene, 2001). Oxidative stress-inducing teratogens, such as alcohol (Sulik et al., 1988), retinoic acid (Williams and Bohnsack, 2019), and nicotine (Zhao and Reece, 2005; Schneider et al., 2010), can also increase the likelihood of embryos born with craniofacial anomalies. Persistent oxidative stress can impinge on neural crest cell development through distinct mechanisms such as DNA damage, p53 activation and autophagy (Wang et al., 2015; Sakai et al., 2016; Han et al., 2019; Cao et al., 2020). Consistent with this idea, DNA damage and genome instability are associated with an increased incidence of cleft lip and/or palate (Kobayashi et al., 2013). Furthermore, mutations in DNA damage repair genes can result in craniofacial malformations, highlighting the importance of maintaining genome stability during normal craniofacial morphogenesis (Wong et al., 2003; Seeman et al., 2004; Altmann and Gennery, 2016; Sakai et al., 2016; Kitami et al., 2018; Boone et al., 2019; Yamaguchi et al., 2021). This led us to postulate that exogenous stressors, particularly oxidative stress and DNA damage, can worsen the damage caused by a particular neural crest cell disruptive mutation, thus exacerbating its phenotypic outcome. In this review, we provide a brief overview of cranial neural crest cell development and the effects of diabetes and oxidative stress on craniofacial morphogenesis. We will also discuss potential mechanisms for oxidative stressinduced DNA damage in modulating the phenotypic variability associated with craniofacial disorders.

\section{NEURAL CREST CELL AND CRANIOFACIAL DEVELOPMENT}

Underpinning the complex morphogenesis of head and facial development is a population of cells called neural crest cells (NCC). Considered a vertebrate-specific cell type, NCC are transiently generated during the neurulation phase of embryogenesis which corresponds to about 3-4 weeks of human development. Specified in the neural ectoderm along nearly the entire length of the embryo, NCC undergo an epithelial-to-mesenchymal transition (EMT), which facilitates their delamination and migration throughout the primitive head. Cranial NCC give rise to the chondrocytes and osteoblasts of cartilage and bone, the fibroblasts of connective tissue, the odontoblasts in teeth, the sensory neurons and glia in the peripheral nervous system, and the pigment cells in the skin (Le Douarin and Kalcheim, 1999; Bronner and LeDouarin, 2012). Ultimately, there is barely a tissue or organ throughout the entire body that does not receive a contribution from NCC. Given this remarkable differentiation capacity, NCC have been described as the fourth primary germ layer (Hall, 1999). The specification of neural crest cell progenitors is thought to occur during gastrulation in the neural plate border (Trainor and Krumlauf, 2001, 2002; García-Castro et al., 2002; Basch et al., 2006; Prasad et al., 2020). This territory is defined as the junction between the neural ectoderm and the surface ectoderm and in chick embryos is demarcated by the expression of Pax7 (Basch et al., 2006). During neurulation, the two halves of the neural ectoderm or neural plate elevate, converge and fuse to form a neural tube, which is the precursor of the central nervous system (Figure 1A). At the same time, neural crest cells are induced to form in the dorsolateral aspect of the neural plate in response to signals from the surrounding ectoderm, mesoderm, and endoderm. Considerable evidence has shown that signaling cascades mediated by BMP (Bone Morphogenetic Protein), FGF (fibroblast growth factor), and Wnt (Wingless/Int) play central roles in neural crest induction, although the importance and spatiotemporal regulation of these individual signaling pathways varies depending on the species (Bae and SaintJeannet, 2014). The potential reasons for, and significance of, these species-specific differences have been previously discussed (Barriga et al., 2015).

Irrespective of which signaling pathways are involved, the formation of NCC involves tremendous cytoskeletal changes. During EMT, adjoining neuroepithelial cells lose their intracellular tight junctions, adherens junctions, and apicobasal polarity, and acquire focal adhesions, become polarized and migratory (Taneyhill and Padmanabhan, 2014). These changes in cell adhesion are mediated in part by a "Cadherin switch" in which E-cadherin expression is downregulated in concert with N-cadherin upregulation (Hatta and Takeichi, 1986; 


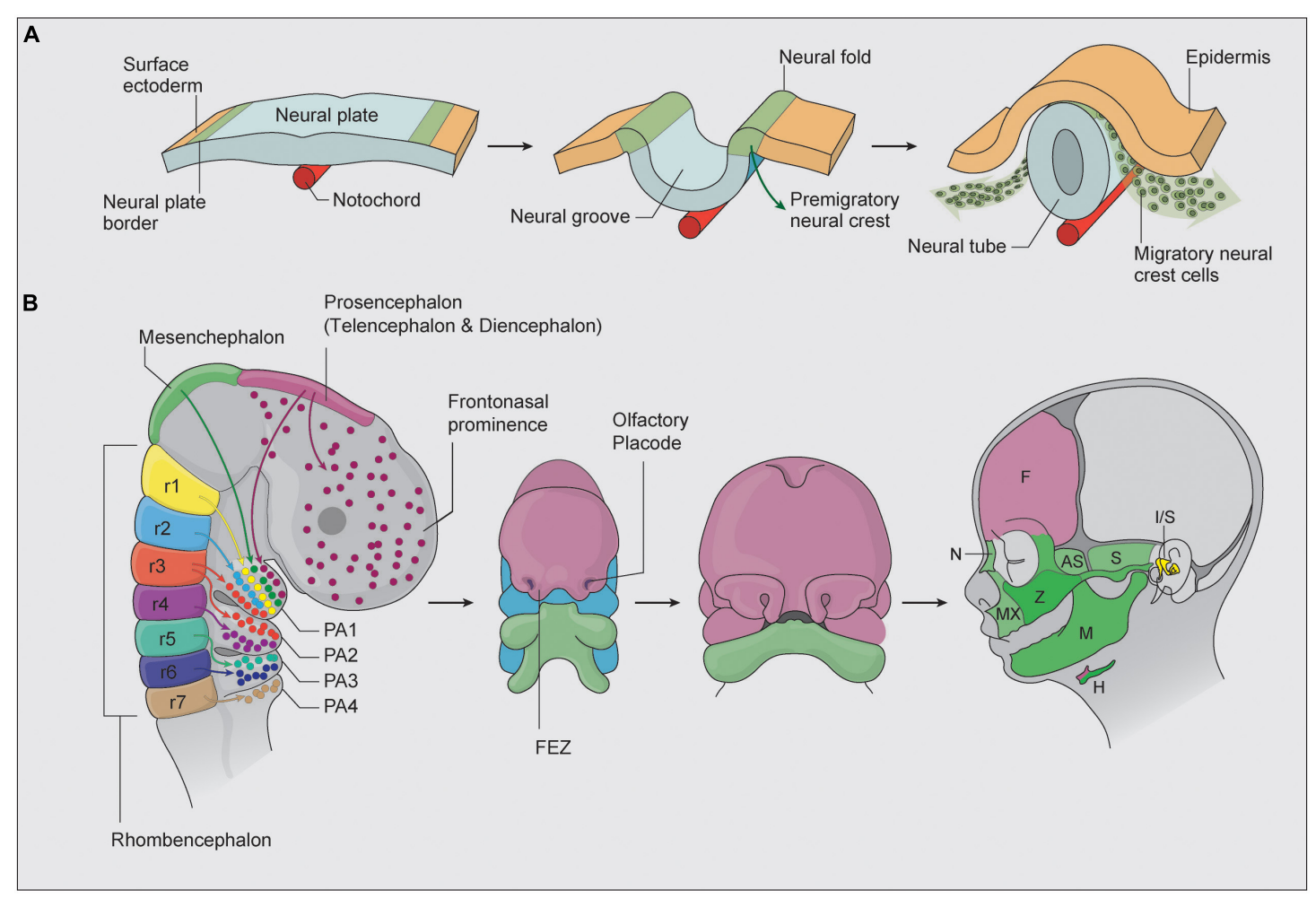

FIGURE 1 | (A) NCC are initially specified within the neural plate border. As the two halves of the neural plate elevate to form a neural tube, NCC are induced and undergo EMT, after which they migrate and colonize the frontonasal prominences, first, second, third, and fourth pharyngeal arches (adapted from Simões-Costa and Bronner, 2015). (B) Cranial NCC patterns of migration and differentiation into the bone and cartilage of the head and face. During embryogenesis, the brain is specified into prosencephalon (diencephalon and telencephalon), mesencephalon, and rhombencephalon regions. The colors highlight regions of the developing face that correspond to NCC populations of different axial origins. The facial prominence and pharyngeal arches then undergo complex morphogenesis to form the structures of the face. AS, alisphenoid bone, F, frontal bone, FEZ, frontonasal ectodermal zone, FNP, frontonasal prominence, H, hyoid bone, I/S, incus and stapes, M, mandible, MX, maxilla, N, nasal bone, PA, pharyngeal arches, r, rhombencephalon, S, squamosal, Z, zygomatic bone.

Coles et al., 2007). A number of transcription factors including members of the Snail, Zeb and Twist protein families play critical roles in NCC EMT (Nieto et al., 1994; Van De Putte et al., 2003; Coles et al., 2007; Mayor and Theveneau, 2012) in part through directly repressing the transcriptional activity and function of E-cadherin (Cano et al., 2000). However, again there are species-specific differences in the absolute requirement and functions of these transcription factors in NCC EMT (Barriga et al., 2015). Nonetheless, the induction, EMT, delamination, migration, and differentiation of NCC depends on integrated gene regulatory networks in which many genes and signaling pathways exhibit reiterative functions.

Neural crest cells arise progressively in an anterior-posterior manner along nearly the entire neuroaxis of the embryo and are classified into cranial, cardiac, trunk, vagal, and sacral NCC axial populations. Of particular relevance in this review are the cranial NCC, which generate most of the craniofacial skeleton in vertebrates. Cranial NCC delaminate from the diencephalon (posterior forebrain), mesencephalon (midbrain), and rhombencephalon (hindbrain) and give rise to the majority of the bone, cartilage and connective tissue of the head and face (Figure 1B) (Achilleos and Trainor, 2015). The most anterior cranial NCC migrate collectively and populate the frontonasal and periocular regions, where they contribute to the nasal and frontal bones, the meninges underlying the calvarial bones and most of the suture mesenchyme separating the skull bones. The posterior cranial NCC migrate in discrete segregated streams and populate the pharyngeal arches (Osumi-Yamashita et al., 1994; Tam and Trainor, 1994; Trainor and Tam, 1995; Trainor et al., 2002), where they differentiate into the upper and lower jaw, middle ear, and skeletal structures in the neck (Figure 1B; Chai et al., 2000; Kulesa et al., 2010). Cranial NCC exhibit varying degrees of unipotency, bipotency and multipotency and are capable of differentiating into neurons and glia of the peripheral nervous system, as well as osteochondroprogenitors (Baroffio et al., 1991; Le Douarin et al., 2004; Dupin et al., 2010; Baggiolini et al., 2015). Migrating neural crest cells express Sox10 and Foxd3, and the activity of these factors persist in cranial NCC destined for neuroglial differentiation, but are switched off in osteochondroprogenitors (Bhatt et al., 2013). Conversely, Sox9, a master regulator of chondrogenesis is expressed in cranial NCC destined for cartilage and bone differentiation but is switched off in neuroglia progenitors (Trainor and Krumlauf, 2001; Dash and Trainor, 2020). 
Several mechanisms may account for the ability of NCC to differentiate into diverse cell types and tissues. If the fate of NCC was predetermined at the time of induction, NCC would comprise a heterogeneous mixture of unipotent progenitor cells, with each giving rise to a singular distinct cell type. Their differentiation would therefore be primarily dependent upon intrinsic signals (Bhatt et al., 2013). However as noted above, NCC exhibit varying degrees of cell fate potency, and therefore depend upon a combination of intrinsically expressed factors in concert with extrinsic signals emanating from the tissues they contact during their migration to undergo their proper spatiotemporal patterns of differentiation (Trainor and Krumlauf, 2001; Trainor, 2003, 2013; Trainor et al., 2003; Crane and Trainor, 2006). These key principles of NCC heterogeneity, potency, and plasticity which were determined through classic embryology, lineage tracing, and transplantation studies have been further substantiated by more recent genetic and molecular analyses such as single cell RNA-sequencing (Morrison et al., 2017; Shang et al., 2018; Soldatov et al., 2019). The remarkable lineage potential of NCC, combined with a limited capacity for self-renewal that persists even into adult life, has raised the potential for NCC to be used in regenerative medicine (Crane and Trainor, 2006; Achilleos and Trainor, 2012; Shang et al., 2018).

Synonymous with the "new head" hypothesis (Gans and Northcutt, 1983), cranial NCC carry species-specific programming information that is integral to craniofacial development, evolution, variation, and disease (Noden, 1983; Trainor and Krumlauf, 2001; Schneider and Helms, 2003; Trainor, 2003; Trainor et al., 2003; Noden and Trainor, 2005). Proper craniofacial development therefore requires that an embryo generates and maintains a sufficient number of NCC that proliferate, survive, migrate, and differentiate in the correct spatiotemporal manner. Perturbation of any one of these phases of NCC development can lead to variable craniofacial malformations. A growing body of evidence suggests that NCC are particularly sensitive to exogenous environmental stressors such as diabetes, oxidative stress, and DNA damage (Sakai and Trainor, 2016; Sakai et al., 2016; Kitami et al., 2018; Yamaguchi et al., 2021). We postulate that the interactions between these exogenous stressors and genetic risk factors for individual craniofacial malformations compromise NCC viability, thus contributing to the phenotypic variation observed in many craniofacial syndromes. To illustrate this concept, we discuss craniofacial syndromes with well recognized broad phenotypic variation that are known to be influenced by diabetes, oxidative stress, and DNA damage.

\section{GENE-ENVIRONMENT INTERACTIONS INFLUENCE PHENOTYPE VARIABILITY IN DIFFERENT CRANIOFACIAL DISORDERS}

\section{Treacher Collins Syndrome}

Treacher Collins syndrome (TCS, OMIM number 154500) is a prime example of the considerable phenotypic variability characteristic of congenital craniofacial disorders. Extensive inter- and intra-familial variation is a striking feature of the condition (Dixon et al., 1994; Marres et al., 1995; Jones et al., 2008). TCS is characterized by anomalies of the head and face, including hypoplasia of the facial bones, especially the mandible and zygomatic complex, which may result in dental malocclusion. The palate is often high-arched or cleft (Poswillo, 1975). Other clinical features of TCS include alterations in the shape, size, and position of the external ears, which are frequently associated with atresia of the external auditory canals and anomalies of the middle ear ossicles (Edwards et al., 1996). In the most extreme cases of TCS, the constellation of craniofacial anomalies can result in a compromised airway leading to perinatal death (Edwards et al., 1996). In contrast, some individuals can be so mildly affected that it is difficult to establish an unequivocal diagnosis. It is therefore not uncommon for mildly affected TCS patients to be diagnosed retrospectively, after the birth of a more severely affected child or sibling.

TCS occurs with an estimated incidence of 1 in 50,000 live births (Carey, 1992; Twigg and Wilkie, 2015) and is caused primarily by mutations in the TCOF1 gene. However, TCS is also associated with mutations in POLR $1 B, P O L R 1 C$ and POLR1D. With respect to TCOF1 the mode of inheritance is autosomal dominant, although very rare cases of autosomal recessive mutations have been observed (Dixon et al., 1996; Edwards et al., 1997). For POLR1B, all mutations to date appear to be autosomal dominant, whereas for POLR1C they are autosomal recessive (Dauwerse et al., 2011; Ghesh et al., 2019; Sanchez et al., 2020). In contrast, both autosomal dominant and recessive mutations in POLR1D have been reported in association with TCS (Dauwerse et al., 2011).

Hundreds of family-specific mutations including deletions, insertions, splice site, missense, and nonsense mutations have been identified in the TCOF1 gene (databases.lovd.nl/shared/genes/TCOF1). However, irrespective of the position of the mutation, or the type of mutation, or whether the mutation is maternally or paternally inherited, these factors apparently have no impact on the severity of the TCS condition, and there does not appear to be any significant sex-based difference in the effect of a mutation on male vs. female offspring. Although the penetrance of genetic mutations underlying TCS is high, approximately $60 \%$ of cases arise randomly or spontaneously as a result of a de novo mutation in a family without a history of the disorder. The high degree of variability in which individuals with TCS are affected, together with the high rate of de novo mutations and the absence of a strong genotype-phenotype correlation, renders the provision of genetic counseling complicated, particularly where the diagnosis of an affected child's parents is equivocal (Trainor et al., 2009).

TCOF1 encodes the nucleolar phosphoprotein Treacle, which together with Upstream Binding Factor (UBF) stimulates transcription of ribosomal DNA by RNA Polymerase I (Valdez et al., 2004). POLR1B is a catalytic core subunit of RNA Polymerase I, whereas POLR1C and POLR1D comprise core subunits of RNA Polymerases I and III. Each of these factors play essential roles in rDNA transcription, which is the first step and a rate limiting step in ribosome biogenesis. Ribosome biogenesis 
is the process of making ribosomes, the ribonucleoprotein machines that translate mRNA into protein, thus synthesizing proteins within all cells. Since ribosomes underpin protein production, their synthesis consumes a cell's metabolic capacity, and ribosome biogenesis is therefore tightly integrated with and regulates many cellular processes including proliferation, survival, growth, and differentiation. Interestingly, deficiencies in rDNA transcription and ribosome biogenesis result in the activation and stabilization of p53 and ultimately cell death (Rubbi and Milner, 2003). Loss-of-function mouse and zebrafish models of TCOF1, POLR1B, POLR1C or POLR1D homologs exhibit extensive p53 dependent neuroepithelium and neural crest cell apoptosis, which presages hypoplasia of the craniofacial skeleton, mimicking the characteristic features of TCS in humans (Dixon et al., 2006; Jones et al., 2008; Noack Watt et al., 2016; Sanchez et al., 2020). Furthermore, pharmacological or genetic inhibition of p53-dependent apoptosis prevents TCS in animal models (Jones et al., 2008; Noack Watt et al., 2016). TCS is therefore primarily associated with perturbation of rDNA transcription and a subsequent deficiency in the ribosome biogenesis and protein translation necessary for neuroepithelial neural crest cell proliferation and survival (Dixon et al., 2006; Noack Watt et al., 2016).

The $\mathrm{p} 53$ inhibition rescue of TCS occurred without restoration of ribosome biogenesis (Jones et al., 2008). This led to the suggestion that Tcof1/Treacle may also perform non-rDNA transcription and ribosome biogenesis associated functions during development. Treacle was subsequently found to directly interact with the MRNM (MDC1-RAD50-NBS1-MRE11) complex (Sakai et al., 2016), which mediates the double-stranded DNA damage response. In support of this observation, two other studies focused on the role of NBS1 in response to DNA damage induced by laser microirradiation in cultured cells, identified TCOF1/Treacle as a direct binding partner of NBS1 (Ciccia et al., 2014; Larsen et al., 2014; Sakai et al., 2016). Collectively, this implied that TCOF1 might play a key role in the response to DNA damage via the MRNM complex. Treacle was subsequently shown to localize to sites of DNA damage and Tcof1 $1^{+/-}$ embryo-derived mouse embryonic fibroblasts (MEFs) exhibited a delay in DNA damage repair (Sakai et al., 2016). Furthermore, p-ATM was observed to be upregulated in Tcof1 $1^{+/-}$embryos compared to control littermates, and $\gamma$-H2AX, p-Chk 2 and $\mathrm{p} 53$ were activated in the same neuroepithelial cells undergoing apoptosis in vivo in Tcof1 ${ }^{+/-}$embryos (Sakai et al., 2016). Treacle-dependent NBS1 translocation regulates silencing of RNA polymerase I-dependent rRNA transcription upon DNA damage (Ciccia et al., 2014; Larsen et al., 2014; Sakai et al., 2016), and interestingly in the absence of Treacle, BRCA1 no longer localizes to sites of DNA damage (Sakai et al., 2016). These results provided direct evidence that TCOF1/Treacle functions in the DNA damage response and repair pathway in vivo (Sakai et al., 2016). Furthermore, it connected deficient DNA damage repair and the p53 dependent apoptotic elimination of cranial NCC in Tcof1 $1^{+/-}$embryos as a component of the cellular and developmental mechanisms underlying the pathogenesis of TCS.

Neuroepithelial cells including progenitor neural crest cells endogenously generate high levels of reactive oxygen species
(ROS) compared to other tissues during embryogenesis (Sakai et al., 2016). Furthermore, exposing wild-type embryos to strong oxidants such as 3-nitropropionic acid or $\mathrm{H}_{2} \mathrm{O}_{2}$ induces apoptosis specifically in the neuroepithelium and progenitor neural crest cells. Thus, not only do these cells naturally exist in a highly oxidative state, they are also particularly sensitive to exogenous ROS (Sakai and Trainor, 2016; Sakai et al., 2016). Furthermore, mutations in genes critical for responding to and repairing DNA damage, would increase the sensitivity to exogenous ROS as is the case in $T c o f 1^{+/-}$embryos (Sakai et al., 2016). Conversely, antioxidant supplementation provided a therapeutic avenue for ameliorating or even preventing ROS induced DNA damage phenotypes. Treating Tcof1 $1^{+/-}$embryos in utero with a strong antioxidant such as $\mathrm{N}$-acetylcysteine is able to clear the ROS, thereby preventing DNA damage, p53 activation and apoptosis. Consequently, about $30 \%$ of antioxidant treated Tcof $1^{+/-}$embryos were fully rescued and morphologically indistinguishable from their wild-type littermates (Sakai et al., 2016). Thus, Tcof1/Treacle plays an essential role in protecting neuroepithelial and neural crest cells from endogenous and exogenous oxidative stress-induced DNA damage during normal craniofacial development. Consistent with this idea, a SILAC analysis of oxidative stress-mediated proteins in human pneumocytes revealed a potential role for Treacle in oxidant defense (Duan et al., 2010). Given that the in utero gestational environment generates and is subjected to dynamic levels of oxidative stress that fluctuate during an individual pregnancy and vary between pregnancies, these results imply that differential levels of oxidative stress contribute to the inter- and intra-familial variability in craniofacial anomalies characteristic of TCS (Figure 2).

The inter-and intra-familial phenotypic variability observed in association with TCS in humans can be reproduced experimentally in mice with mutations in Tcof1 on different genetic backgrounds (Dixon and Dixon, 2004). This illustrates the potential for complex interactions between Tcof1 and intrinsic background-specific modifier genes, or extrinsic environmental factors, in modulating phenotype variability and severity. In fact, it is tempting to speculate that a combination of endogenous background specific levels of TCOF1/Treacle, genetic modifiers and levels of ROS collectively determines TCS phenotypic outcomes.

\section{Holoprosencephaly}

A complex genotype-phenotype relationship has also been observed in holoprosencephaly (HPE; OMIM number 236100), which affects approximately 1 in 16,000 live births (Geng and Oliver, 2009). HPE is a structural brain malformation characterized by incomplete or absent division of the forebrain (prosencephalon) into two cerebral hemispheres, which normally occurs by the 5th week of gestation (Golden, 1999; Kruszka and Muenke, 2018). HPE may present as an isolated phenotype (nonsyndromic) or as part of a syndrome (syndromic), the most common of which include Trisomy 13 and 22, as well as SmithLemli-Opitz syndrome and Hartsfield syndrome (Kruszka and Muenke, 2018). Non-syndromic HPE is commonly associated with pathogenic variants in one of four principal genes including 


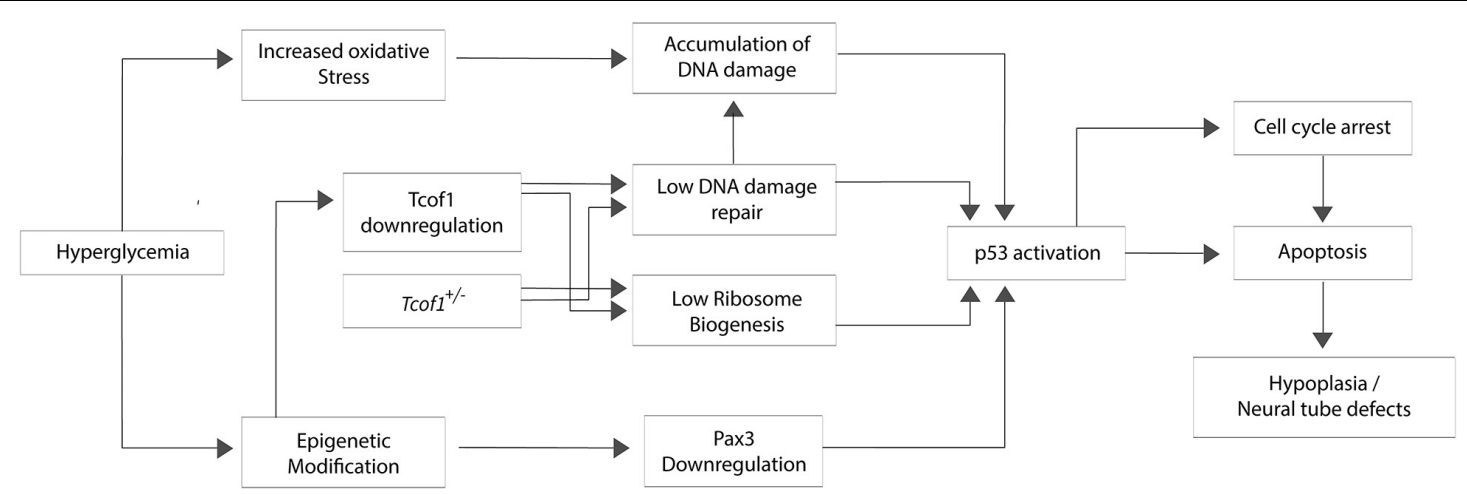

FIGURE 2 | Potential mechanisms for hyperglycemia, oxidative stress, and DNA damage in the pathogenesis of Treacher Collins syndrome. The hyperglycemic environment characteristic of maternal diabetes can lead to oxidative stress and epigenetic modification. Oxidative DNA damage and aberrant Pax3 silencing lead to p53 activation which induces apoptosis particularly within neuroepithelial cells and neural crest cells, resulting in neural tube defects or hypoplasia of neural crest-derived tissues.

SHH, ZIC2, SIX3, and TGIF (Roessler et al., 1996, 2009; Solomon et al., 2009; Taniguchi et al., 2012). Other genetic loci, such as GLI2, CDON (also known as CDO), FGF8, and DISP1 have also been associated with HPE or HPE-like phenotypes at lower frequency (Roessler et al., 2003, 2009; Bae et al., 2011; Hong et al., 2018).

Similar to TCOF1 mutations in TCS, the phenotypic consequences of loss-of-functions mutations in these HPE associated loci correlate with a spectrum of facial malformations, ranging from non-lethal microforms such as hypotelorism, midfacial hypoplasia, and a single maxillary incisor, to an extremely severe form characterized by cyclopia and proboscis (Solomon et al., 2010). Depending on the degree of separation between the cerebral hemispheres, HPE is generally classified into four main subtypes: alobar, semilobar, lobar, middle interhemispheric (Solomon et al., 2010), together with a new classification called septopreoptic variant (Hahn et al., 2010). In alobar HPE, the lateral and third ventricles are completely fused, resulting in the absence of midline separation between cerebral hemispheres. Semilobar HPE occurs when the interhemispheric fissure, or the dividing line between left and right side of the brain, is only present posteriorly. In the less severe lobar HPE, the cerebral hemispheres are mostly divided except for the rostral portion of the frontal cortex. Meanwhile, the middle interhemispheric variant of HPE is characterized by the presence of interhemispheric fissure only in the anterior and posterior part of the brain, which results in medial cerebral hemispheres fusion. Lastly, the septopreoptic variant is considered the mildest form of HPE, with fusions only present in the septal and/or preoptic regions of the brain (Petryk et al., 2015). In clinical settings, many patients with HPE fall within the border zone of neighboring subtypes, and thus HPE is postulated to exist as a continuum of phenotypes rather than discrete subtypes (Hahn and Barnes, 2010).

The pathogenesis of HPE is complex and involves both genetic causes and environmental risk factors. HPE occurs due to defective development of the axial midline, which is largely orchestrated by Sonic hedgehog (SHH), BMP,
FGF, WNT, Nodal, and retinoic acid signaling pathways (Grinblat and Lipinski, 2019). SHH signaling from the ventral midline is especially crucial for the outgrowth and patterning of developing brain. During embryogenesis, the brain is partitioned into prosencephalon, mesencephalon, and rhombencephalon (Figure 1B). While all three regions undergo further compartmentalization, the most relevant region in HPE pathogenesis is the prosencephalon or forebrain, which is further divided anteriorly into the telencephalon and posteriorly into the diencephalon. Unlike TCS, the craniofacial phenotypes associated with HPE do not come primarily from excessive apoptosis within the neural tube but instead are consequences of the molecular reprogramming of $\mathrm{SHH}$ signaling activity (Cordero et al., 2004; Richbourg et al., 2020). Nonetheless, apoptosis within cranial NCC due to aberrant Shh signaling can add to the severity of HPE (Cordero et al., 2004).

$\mathrm{SHH}$ plays a key role in coordinating dorsoventral polarity of the forebrain by establishing ventral identity in the neural tube during early embryogenesis (Ericson et al., 1995). Hedgehog $(\mathrm{HH})$ proteins undergo lipid modifications and are anchored to the membrane of the producing cells prior to secretion. After being released from the cell membrane by Dispatched (DISP1), $\mathrm{HH}$ then binds to its receptor $\mathrm{PTCH}$, which subsequently relieves the inhibition of SMO facilitating signaling through the GLI protein family (Burke et al., 1999; Ruiz and Altaba, 1999; Denef et al., 2000). Other HH-binding proteins, such as BOC, CDO, and GAS1 may act as co-receptors to enhance SHH signaling activity (Tenzen et al., 2006; Allen et al., 2007). Considering the central role that $\mathrm{SHH}$ signaling plays during midfacial development, it is perhaps unsurprising that mutations in $\mathrm{SHH}$ loci are the most common genetic cause of HPE in humans (Roessler et al., 2018). However, individuals with $\mathrm{SHH}$ mutations display incomplete penetrance, with only about $37 \%$ of carriers actually developing HPE (Roessler et al., 1996). Similarly, mutations in other SHHrelated genes such as GLI2 and ZIC2 lead to HPE with variable severity. This indicates that haploinsufficiency for the respective genes alone is insufficient to elicit the full spectrum of HPE phenotypes (Petryk et al., 2015). 
The variable severity of HPE may be associated with the time at which $\mathrm{HH}$ signaling is disrupted (Cohen, 2006), or a dose-dependent decrease in signaling activity. In 1908, anatomist Harris Wilder postulated the "Morphology of Cosmobia" where he speculated that a spectrum of symmetrical anomalies of the face was due to "some modification in the germ itself, leading the organisms to develop in accordance with laws as definite and natural, though not as usual, as those governing normal development" (Wilder, 1908). This spectrum of facial anomalies in effect corresponds to a gradient of Shh signaling activity, where elimination or a significant reduction in Shh signaling leads to cyclopia, a severe form of HPE characterized by a single median eye and proboscis, while in contrast, increased Shh signaling can result in facial duplication (Wilder, 1908; Figure 3). In support of this idea, work in chick embryos has shown that varying the level of Shh signaling affects the induction and spatial organization of the frontonasal ectodermal zone (FEZ) (Cordero et al., 2004), and alters dorsoventral patterning of the forebrain (Brugmann et al., 2010), each of which results in significant changes in facial appearance.

Animal models provide evidence for a functional threshold level of Shh signaling below which HPE phenotypes are always severe. In mice, homozygous mutation of Shh results in cyclopia and proboscis, leading to embryonic lethality, whereas Shh heterozygous mice are morphologically normal (Chiang et al., 1996). Genetic background also has a major effect on the penetrance of HPE phenotypes in mice. For instance, a homozygous mutation of Cdo on a 129S6/SvEvTac background results in mild facial microforms of HPE, whereas on a C57BL/6NTac background results in phenotypes similar to semilobar HPE (Chiang et al., 1996). Other intrinsic signaling pathways affecting the level of Shh expression may also contribute to HPE phenotypic variation. For example, mutations of Tgif, which maintains the balance between Shh and its antagonist Gli3 (Taniguchi et al., 2012), result in a more severe HPE phenotype when coupled with Shh haploinsufficiency compared to phenotypes from individual mutations alone (Chiang et al., 1996). Tgif protein can bind to a retinoic acid response element (RARE) in Cyp26a1, which plays a critical role in anteriorposterior patterning of the forebrain through the degradation of retinoic acid (Gongal and Waskiewicz, 2008). Sub-teratogenic doses of retinoic acid, which are often prescribed to treat skin conditions, thereby sensitize embryos to Tgif mutations (Bartholin et al., 2006). This supports the notion of a Shh threshold, where any additional stress, be it from genetic factors or the environment, can lower Shh expression below the level at which HPE always manifests (Bartholin et al., 2006).

Major environmental risk factors implicated in human HPE include maternal diabetes and ethanol exposure, which converge on $\mathrm{SHH}$ signaling. Around 1-2\% of infants born from diabetic mothers develop HPE and women with gestational diabetes have twice the risk for HPE compared to control mothers (Petryk et al., 2015). Maternal hyperglycemia can disrupt the oxidantantioxidant balance in the embryos and increase oxidative stress, increasing the severity of HPE (Zhao and Reece, 2005; Figure 3). Similarly, ethanol exposure impairs Shh expression and causes defects in midline development. Ethanol activates PKA, a negative regulator of Shh signaling, in the anterior prechordal mesendoderm during midline specification, and subsequently induces apoptosis (Lepage et al., 1995; Pan and Rubin, 1995; Hammerschmidt et al., 1996; Ahlgren and Bronner-Fraser, 1999; Aoto et al., 2008). Both ethanol-induced cranial neural crest cell death and associated craniofacial growth defects can be rescued by exogenous Shh, suggesting that craniofacial anomalies

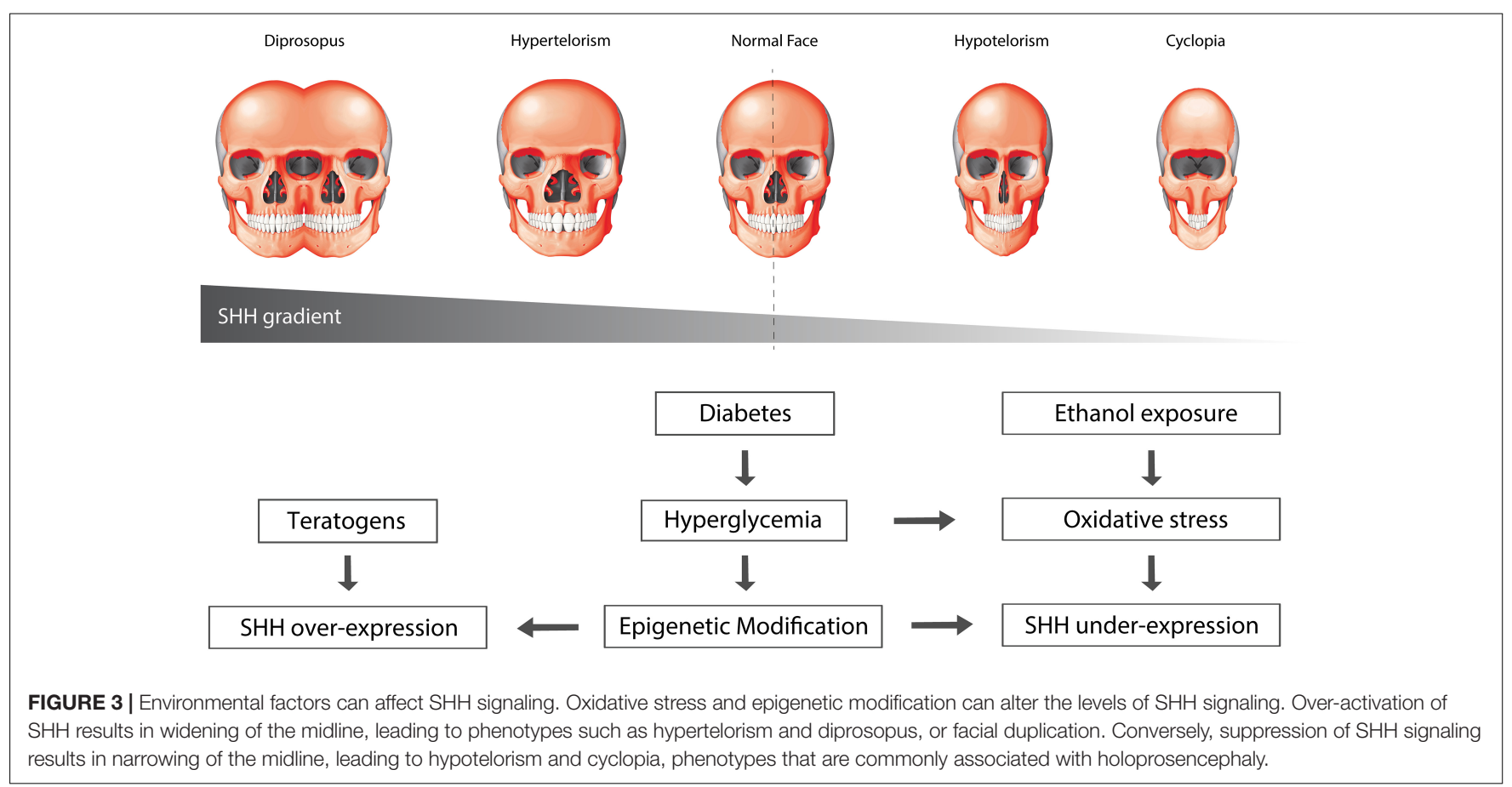


resulting from fetal alcohol exposure are caused at least partially by loss of Shh and its effects on neural crest cell survival (Ahlgren et al., 2002). In addition, dietary antioxidant supplementation can prevent the abolition of Shh expression as well as apoptosis in a dose-dependent manner. This indicates that oxidative stress can downregulate Shh expression and may contribute to the phenotypic variability observed in $\mathrm{SHH}$ heterozygous patients (Aoto et al., 2008). More recently, ethanol was shown to synergize directly with Cdo mutations to suppress Shh expression and elicit severe HPE on a 129S6 background, which would otherwise only exhibit a mild phenotype (Hong and Krauss, 2017). Interestingly, antioxidant treatment did not alter the frequency or severity of HPE phenotypes in these mice despite normalization of ROS levels. These conflicting results suggest that ethanol's teratogenicity may occur via multiple mechanisms depending on the genetic background and developmental context.

With respect to the HPE continuum, a functional ceiling is likely to exist where Shh signaling above a certain level can induce replication stress and DNA damage. Consistent with this idea, overexpression of the Shh co-receptor gene $B O C$ results in elevated Shh-induced replication stress and DNA damage, which increases the incidence of Ptch loss-of-heterozygosity, leading to constitutive activation of Shh signaling (Mille et al., 2014). It is well-known that Ptch gain-of-function can cause HPE due to ventralization of the neural tube and incorrect specification of the forebrain (Goodrich et al., 1999; Mullor and Guerrero, 2000), however, it has yet to be determined whether rescuing DNA damage can ameliorate the effect of Shh over-activation in this case. Aside from replication stress, mutations resulting in excessive Shh signaling lead directly to increased proliferation of neural crest cells, which can manifest as hypertelorism and frontonasal dysplasia (Mille et al., 2014). Furthermore, mouse embryos derived from dams with streptozotocin-induced diabetes exhibit expanded Shh expression in the ventral telencephalon, which leads to a phenotype similar to the middle interhemispheric variant of HPE (Brugmann et al., 2010). Taken together, the variable expressivity of similar HPE gene mutations can be attributed to co-morbid genetic interactors and environmental modifiers.

\section{DIABETES, OXIDATIVE STRESS AND DNA DAMAGE AFFECT CRANIOFACIAL DEVELOPMENT AND MODULATE PHENOTYPE VARIBILITY IN CRANIOFACIAL SYNDROMES}

\section{Hyperglycemia in Diabetic Pregnancy Alters Cellular Metabolism and Increases Oxidative Stress}

Maternal diabetes involves systemic metabolic changes which can affect virtually any organ system, but the craniofacial, central nervous system and cardiovascular structures are primarily affected (Becerra et al., 1990). These diabetic pregnancy-induced malformations, collectively termed diabetic embryopathy, are thought to arise due to defects in neurulation and neural crest cell development during the early stages of organogenesis, which corresponds to approximately the first 8 weeks of human gestation (Mills et al., 1979; Li et al., 2005; Fetita et al., 2006; Loeken, 2006). The prevalence for women with either type 1 or type 2 diabetes to be at high risk for giving birth to babies with diabetic embryopathy (Towner et al., 1995), suggests a fundamental causal role for hyperglycemia and increased glucose uptake to the embryo via glucose transporters (Loeken, 2020).

Excessive glucose metabolism increases oxidative phosphorylation (OXPHOS) and the production of reactive oxygen species (ROS), which induces a state of oxidative stress if not balanced by increased antioxidant capacity (Wentzel and Eriksson, 2011; Kim et al., 2017; Loeken, 2020). Intracellular ROS such as superoxide $\left(\mathrm{O}_{2}^{-}\right)$is primarily produced via the oxidation of NADPH or by the partial reduction of oxygen during aerobic respiration in mitochondria. Superoxide can be converted into hydrogen peroxide $\left(\mathrm{H}_{2} \mathrm{O}_{2}\right)$ by superoxide dismutases, which then either oxidizes cysteine residues on proteins or becomes converted to $\mathrm{H}_{2} \mathrm{O}$ by cellular antioxidant proteins such as catalase, glutathione peroxidase or peroxiredoxins. If high levels of $\mathrm{H}_{2} \mathrm{O}_{2}$ levels go unchecked, hydroxyl radicals $\left(\mathrm{OH}^{-}\right)$ will form and this can result in molecular, cellular, and tissue damage during embryogenesis (Jones and Sies, 2015). However, increased oxidant status is complex, involving a combination of increased superoxide production as well as impaired free radical scavenging, although the pathways responsible for increased oxidant status have not been completely elucidated. Interestingly, early embryonic development is especially vulnerable to oxidative stress due to the lack of free radical scavenging enzymes activity (El-hage and Singh, 1990). In fact, premigratory and migratory NCC appear to be particularly at risk of free radical damage since they are deficient in superoxide dismutase and catalase activity, which are necessary for the normal inactivation of superoxide, hydrogen peroxide and hydroxyl radicals (Davis et al., 1990; Chen and Sulik, 1996). This is consistent with the neuroepithelium from which NCC originate, existing in a highly oxidative state and being particularly sensitive to exogenous oxidative stress (Sakai et al., 2016), thus indicating that cranial NCC possess lower tolerance to the detrimental effect of increased ROS.

High glucose metabolism in NCC may be attributable to their rapid proliferation and motile nature, reminiscent of the Warburg effect in cancer metastasis (Warburg, 1956). Actively dividing cells favor glucose metabolism through aerobic glycolysis to produce biomass. In contrast, terminally differentiated cells rely on OXPHOS to generate energy more efficiently from glucose (Warburg, 1956). Cellular glucose metabolism thus alternates between aerobic glycolysis and OXPHOS depending on the stage of development. During EMT, neural crest cells undergo similar cytoskeletal and molecular changes observed in metastatic tumor cells where aerobic glycolysis is increased to serve the anabolic demand of proliferation. Enhanced aerobic glycolysis promotes the Yap/Tead pathway that is necessary for cell delamination during EMT (Bhattacharya et al., 2020). Conversely, the decay of glycolytic activity and increased OXPHOS correlate with the 
loss of mesenchymal motility (Warburg, 1956), suggesting that hyperglycemia may accelerate the differentiation of neural crestderived tissues through preferential switching to OXPHOS. Additionally, hyperglycemia-induced oxidative stress leads to the oxidation of cholesterol, lipids, and proteins, which have been proposed to contribute to the pathology of SmithLemli-Opitz syndrome (Richards et al., 2006) and thus may add to the phenotypic variability of HPE. Since proper Shh gradient formation is dependent upon cholesterol modification, oxidation of cholesterol can directly impact Shh signaling and impair neural tube patterning (Guerrero and Chiang, 2007; Porter and Herman, 2011). More studies are still needed to understand whether untimely switching to OXPHOS and increased cholesterol oxidation contribute to increased risk of craniofacial malformation or variation in craniofacial development. However, it is clear that improper fluctuations of glucose metabolism in diabetic embryopathy can adversely affect NCC EMT and migration as well as neural tube patterning, resulting in craniofacial malformations.

\section{Hyperglycemia-Induced Oxidative Stress Leads to Epigenetic Modifications and Altered Gene Expression}

One of the negative effects of excess ROS is that it can disrupt key signaling events during cellular differentiation, resulting in structural abnormalities (Kemp et al., 2008). In fact, many developmental genes exhibit specific sensitivities to hyperglycemic conditions and changes in the cellular redox state (Fetita et al., 2006; Wu et al., 2012). This may be due in part to the presence of binding sites for transcription factors involved in response to oxidative stress in their promoters (Pavlinkova et al., 2009). These genes which were identified under the conditions of maternal diabetes, and in the absence of genetic alterations, are therefore subject to gene-environment interactions in their response to the intrauterine environment of a diabetic pregnancy. Further evidence indicates that environmental factors can perturb gene regulation, which may affect gene dosage variability in individuals from different genetic backgrounds (Phelan et al., 1997). For instance, both diabetes and oxidative stress can impair Shh signaling by increasing or reducing Shh expression, which leads to defects in neural tube patterning (Pavlinkova et al., 2009). Furthermore, maternal diabetes increases the overall variability of gene expression levels in embryos, including deregulation of genes involved in Wnt, Hedgehog, and Notch signaling (Salbaum and Kappen, 2010). Additionally, diabetes-induced oxidative stress results in reduced expression of Pax3, which plays a major role in neuroepithelial development (Pavlinkova et al., 2009; Salbaum and Kappen, 2010). Pax3 loss-of-function results in aberrant p53 activation, neuroepithelium and neural crest cell apoptosis, and consequently neural tube defects (Liao et al., 2004; Aoto et al., 2008) as well as malformation of structures derived from neural crest cells (Loeken, 2006; Wu et al., 2012).

Epigenetic factors, such as DNA methylation and histone modification, may also contribute to this variability through gene silencing or aberrant activation. In fact, hyperglycemia and oxidative stress were shown to trigger chromatin modifications via histone and DNA methylation. Mouse neural stem cells derived from the embryos of diabetic mothers exhibit increased global histone $\mathrm{H} 3 \mathrm{~K} 9$ trimethylation and DNA methylation, as well as decreased histone $\mathrm{H} 3 \mathrm{~K} 9$ acetylation which leads to altered miRNA expression (Shyamasundar et al., 2013; Ramya et al., 2017). Alteration of miRNA activity can impair autophagy and lead to neural tube defects such as exencephaly (Xu et al., 2013; Wang et al., 2017). The same phenomena were also observed in human neural progenitor cells in which high glucose modifies the DNA methylation pattern of neurodevelopment-associated genes, hence affecting their activity (Kandilya et al., 2020). These findings suggest that hyperglycemia can interact with genetic loci by influencing the activities of histone-modifying and DNA methyltransferase enzymes. Indeed, increased activity of DNA methyltransferase $3 \mathrm{~b}($ Dnmt3b) in mouse embryos and embryonic stem cells (mESC) of diabetic mothers result in decreased methylation of Pax3 CpG island, which leads to silencing of Pax3 (Wei and Loeken, 2014). More importantly, Tcof1 and Cdo were shown to be deregulated in hyperglycemic embryos (Salbaum and Kappen, 2010), indicating that maternal diabetes may exacerbate TCS and HPE phenotypes by directly lowering Tcof1 and Cdo expression even further. It has yet to be determined what epigenetic modification occurs within Tcof1 and Cdo CpG islands, however, hyperglycemia-induced epigenetic modifications potentially underlie gene expression variability in $T \operatorname{cof} 1^{+/-}$or $\mathrm{Cdo}^{-/-}$mutant mice on different genetic background, which may correlate with phenotypic variability in TCS and HPE.

\section{A Potential Role for DNA Damage in Craniofacial Development}

The rapid and sustained proliferation of premigratory and migratory NCC results in naturally high levels of ROS, which if left unchecked can lead to genotoxic stress in the form of DNA damage (Sakai and Trainor, 2016; Sakai et al., 2016). Newborns from mothers with diabetes exhibit elevated levels of 8-OHdG, which is a widely used marker for oxidative nucleotide damage (Gelaleti et al., 2015; Castilla-Peon et al., 2019), and suggests that hyperglycemia can induce DNA damage. In support of this idea, analysis of neurulation-stage mouse embryos showed that hyperglycemia increases the DNA damage marker p-H2AX, which can be suppressed by overexpression of antioxidant SOD1 both in vitro and in vivo. This indicates that the hyperglycemic environment triggers DNA damage and the DNA damage response (DDR) pathway through oxidative stress (Dong et al., 2015).

NCC-derived tissues seem to be particularly sensitive to DNA damage accumulation due to the lower antioxidant capacity and higher level of ROS in the neuroepithelium and progenitor NCC. Global treatment of mouse embryos with the mitochondrial inhibitor 3-nitropropionic acid induces ROS over-production, resulting in elevated levels of DNA damage specifically within the neuroepithelium (Sakai and Trainor, 2016; Sakai et al., 2016). Although ubiquitously expressed and central to cell survival, the localized endogenous spatiotemporal generation of ROS could render the effects of mutations in DDR genes more significant in 
NCC-derived tissues compared to other tissues. This is evident from the phenotypes of mutations in BRCA1, MRE11, RAD50 and NBS1 in humans and in mouse models. Mutations affecting the MRE11-RAD50-NBS1 (MRN) protein complex are known to cause craniofacial anomalies (Chrzanowska et al., 2001; Fernet et al., 2005; Waltes et al., 2009). The MRN complex functions as a DNA damage sensor by recognizing and binding to the broken ends of DNA (Assenmacher and Hopfner, 2004; Paull and Lee, 2005; Stracker and Petrini, 2011) and thus regulates initial and sustained responses to DNA damage. Hypomorphic mutations in NBS1 are associated with Nijmegen breakage syndrome (NBS), which is characterized by distinct facial features including a small lower jaw (Chrzanowska et al., 2012). Similarly, mutations in MRE11 have also been shown to underlie craniofacial anomalies such as a small lower jaw, together with microcephaly as part of the rare Ataxia Telangiectasia-like disorder (Matsumoto et al., 2011). Developmentally, these phenotypes are thought to arise in part through extensive neuroepithelial apoptosis (Kobayashi et al., 2004; McKinnon, 2012), and consistent with these observations in humans, neural stem cell-specific conditional deletion of Nbs1 and Mre11 in mouse embryos results in microcephaly (Frappart et al., 2005).

Further support for the importance of DNA damage repair in neural crest cell and craniofacial development can be found in BRCA1, a tumor suppressor and a key player in the DNA damage response through its central role in homologous recombination (Frappart et al., 2005). BRCA1 dysregulation is associated with non-syndromic cleft lip and palate, which is one of the most common human craniofacial defects (Kobayashi et al., 2013). Knockout of Brcal in mouse embryos results in extensive neuroepithelial cell apoptosis during the early stages of craniofacial development (Gowen et al., 1996; Hakem et al., 1996; Liu et al., 1996). Conditional deletion of Brca1 in NCC in mouse embryos manifests in hypoplastic jaws, cleft palate, and microcephaly. NCC-derived osteogenic progenitors exhibited increased levels of $\gamma$-H2AX and p53 activation, which subsequently led to their apoptosis, resulting in cranioskeletal hypoplasia. Interestingly, the loss of Brcal did not affect osteogenic differentiation, indicating that Brcal-mediated DNA damage repair is critically required for osteoprogenitor survival during craniofacial development (Kitami et al., 2018; Yamaguchi et al., 2021).

These findings illustrate the importance of maintaining genome integrity during NCC development and help to account for why disruptions in a central process such as the DNA damage response can result in tissue-specific developmental defects. Given that the neuroepithelium exists naturally in a highly oxidative state, which lowers its threshold for oxidative stressinduced p53 activation compared to other tissues (Sakai et al., 2016), suppressing p53 function should in theory offer an avenue for the prevention of some craniofacial malformations. Indeed, both pharmacological and genetic inhibition of p53 function can decrease neuroepithelial apoptosis and rescue animal models of TCS (Jones et al., 2008), open neural tube defects (Pani et al., 2002), and HPE (Billington et al., 2011). Preventing p53 activation through maintenance of proper physiological levels of ROS can therefore help avoid the detrimental effects of DNA damage. In support of this idea, NAC antioxidant supplementation ameliorated the TCS phenotype in Tcof1 $1^{+/-}$ mouse embryos via the diminishment of $\gamma$-H2AX, p-Chk2, and p53 (Sakai et al., 2016). Similarly, several studies have shown that administration of antioxidants, particularly vitamins $\mathrm{C}$ or $\mathrm{E}$, or overexpression of superoxide dismutase reduce the incidence of developmental defects in experimental models of intrauterine diabetes and hyperglycemia (Aoto et al., 2008). Taken together, these data reveal the importance of redox homeostasis for proper developmental signaling and cell viability. Redox homeostasis is maintained through a fine balance between oxidants and antioxidants and when an imbalance occurs prolonged oxidative stress can induce genotoxic stress in the form of DNA strand breaks. Maternal diabetes, smoking and alcohol consumption during pregnancy are all factors known to increase maternal ROS levels, which can be damaging to the genomic DNA of embryos (Ornoy, 2007). Thus in the absence of key pathways for detoxifying ROS or DNA damage repair, persistent hyperglycemia-induced oxidative stress can have embryopathic consequences (Wells et al., 2010) or exacerbate the phenotypic severity caused by a particular genetic mutation (Figure 4). Although the full extent of oxidative stressinduced DNA damage remains to be elucidated, multiple studies have indicated that insufficient DNA damage repair capacity, particularly within premigratory and migratory neural crest cells, can lead to craniofacial malformations (Ornoy, 2007). More importantly, this suggests that oxidative stress-induced DNA damage can underpin gene-environment interactions and influence the variable phenotypic severity observed in many craniofacial disorders and syndromes.

\section{CONCLUDING REMARKS AND FUTURE PERSPECTIVES}

The anatomical complexity of the craniofacial complex coupled with the initiation of its development during early embryogenesis renders the head and face prone to malformation. One of the biggest clinical challenges in craniofacial biology is the frequent lack of accurate genotype-phenotype correlation. This illustrates the need for more detailed quantitative phenotyping to accurately capture the full spectrum of variation for an individual craniofacial syndrome, but it also implies that both genetic and environmental factors contribute to the etiology and pathogeneses of craniofacial anomalies. One of the biggest risk factors for increased severity in craniofacial disorders is maternal diabetes (Ewart-Toland et al., 2000; Chappell et al., 2009). Hyperglycemia, which is the hallmark of diabetes, disrupts cellular metabolism, induces over-production of reactive oxygen species (ROS), and dysregulates genes involved in craniofacial development. We postulate that the detrimental effect of any candidate mutation causing a craniofacial anomaly will be amplified by oxidative stress-induced DNA damage in the neuroepithelium and NCC (Figure 4). TCS is a prime example of this synergistic interaction. Haploinsufficiency of Tcof1 not only disrupts rDNA transcription and ribosome biogenesis, which activates p53 thereby diminishing NCC proliferation 


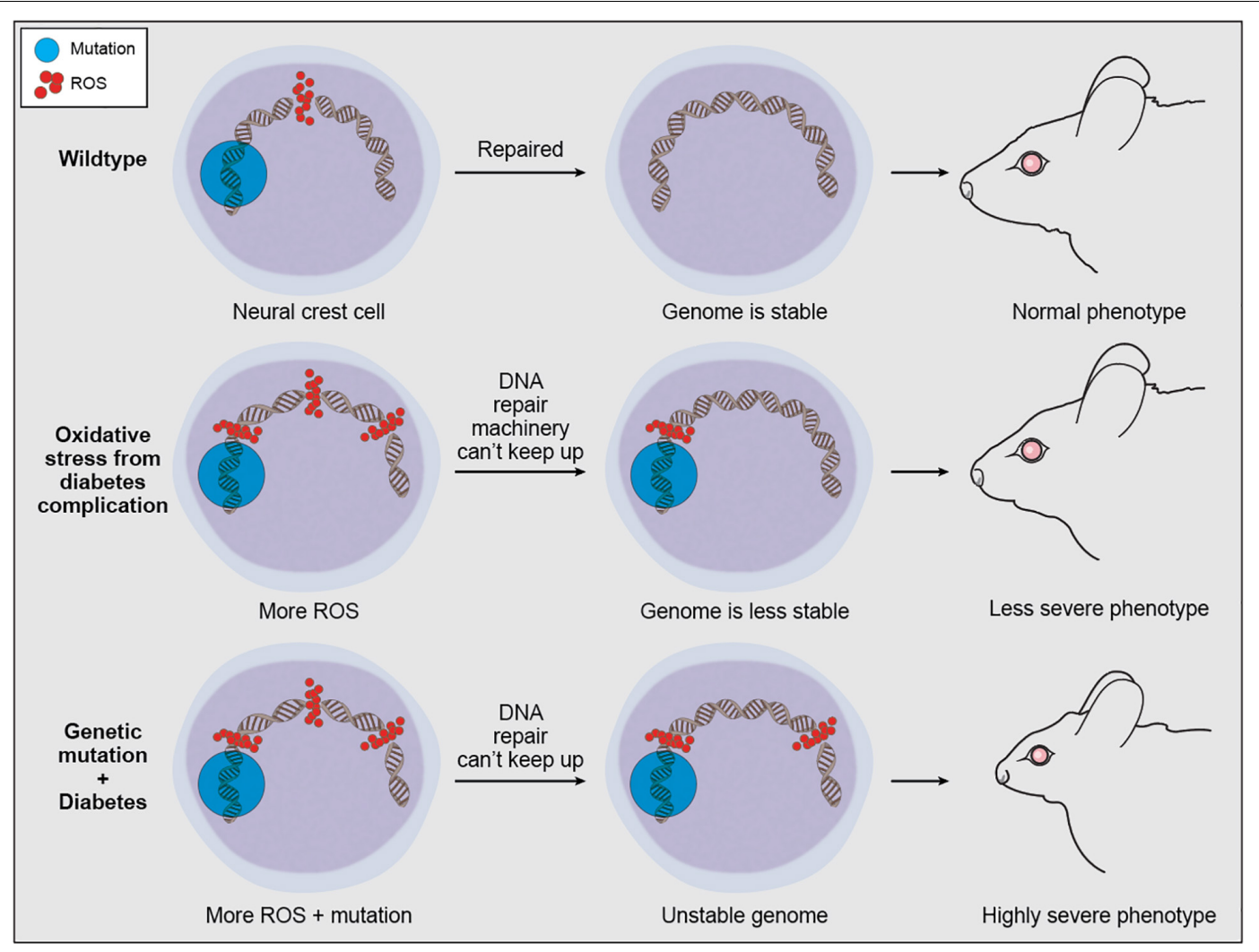

FIGURE 4 | Proposed mechanism of oxidative stress contribution to phenotypic variability in craniofacial anomalies. ROS is a natural byproduct of cellular metabolism which can be scavenged by antioxidant enzymes, and ROS-induced DNA damage within normal levels can be repaired by the DDR machinery. However, continuous exogenous or environmental oxidative stress can overwhelm antioxidant enzymes and DDR capacity, leaving some ROS-induced DNA damage unrepaired. This unrepaired DNA damage can compound the detrimental effects of genetic mutations associated with craniofacial malformations.

and survival, but haploinsufficiency of Tcof1 also perturbs the DNA damage response and affects the ability of $\mathrm{Tcof1}^{+/-}$ embryos to survive under endogenously high levels of oxidation (Dixon et al., 2006; Jones et al., 2008; Sakai et al., 2016). This demonstrates that DNA damage-inducing stress in the gestational environment, such as in the case of maternal diabetes and alcohol exposure, or modifier mutations in DNA damage response and repair genes could therefore affect phenotypic variability and compound TCS severity.

Although the complete mechanisms underpinning the teratogenic effects of maternal diabetes during pregnancy on development are not yet fully understood, it is clear that diabetes-induced oxidative stress, and oxidative stressinduced DNA damage, impacts neuroepithelial and neural crest cell survival and patterning, resulting in significant craniofacial dysmorphogenesis (Aoto et al., 2008). Optimizing maternal metabolic control in the first trimester of gestation during which neurulation and neural crest cell formation and migration occur is therefore critical for protecting newborns against oxidative damage and to ensure normal craniofacial morphogenesis. Suppression of p53-dependent apoptosis appears to be key in preventing many craniofacial anomalies by ensuring survival of neural crest cells throughout development. Although promising, inhibition of p53 poses an unacceptably high risk due to its role as a tumor suppressor. Thus, circumventing p53 activation by maintaining the correct physiological levels of oxidation is a potential avenue for preventing or reducing the severity of craniofacial anomalies. It is important to note however, that lowering ROS too far can pose a cytostatic risk where neural crest cells may not fully grow or differentiate, as well as increase the risk for immunosuppression within the embryo. It is also important to keep in mind that the nature of gene interactions with oxidative stress may differ according to their temporal, spatial, and biochemical context. To date, antioxidant supplementation has only been performed successfully in animal models of craniofacial disorders. Further investigation is needed to elucidate the appropriate dosage, time of administration, and side effects of antioxidant treatment as a viable means for preventing craniofacial anomalies in a clinical setting. Nonetheless, new studies should more extensively investigate the diagnostic and therapeutic value of various oxidative stress biomarkers and antioxidants to reduce oxidative tissue injury to developing newborns. Since phenotypes are frequently affected by gene-environment interactions, examining Quantitative Trait Loci using genetically diverse backgrounds under different environmental conditions may be beneficial for identifying such interactions. Using genome wide association studies (GWAS) to 
identify gene-environment interaction can also be advantageous for identifying high-risk subjects and improving the diagnosis of complex craniofacial diseases.

\section{AUTHOR CONTRIBUTIONS}

SF and PT co-drafted, edited, and revised this review article. Both authors contributed to the article and approved the submitted version.

\section{REFERENCES}

Achilleos, A., and Trainor, P. A. (2012). Neural crest stem cells: discovery, properties and potential for therapy. Cell Res. 22, 288-304. doi: 10.1038/cr.2012. 11

Achilleos, A., and Trainor, P. A. (2015). Mouse models of rare craniofacial disorders. Curr. Top. Dev. Biol. 115, 413-458. doi: 10.1016/bs.ctdb.2015.07.011

Ahlgren, S. C., and Bronner-Fraser, M. (1999). Inhibition of sonic hedgehog signaling in vivo results in craniofacial neural crest cell death. Curr. Biol. 9, 1304-1314. doi: 10.1016/s0960-9822(00)80052-4

Ahlgren, S. C., Thakur, V., and Bronner-Fraser, M. (2002). Sonic hedgehog rescues cranial neural crest from cell death induced by ethanol exposure. Proc. Natl. Acad. Sci.U.S.A. 99, 10476-10481. doi: 10.1073/pnas.162356199

Allen, B. L., Tenzen, T., and McMahon, A. P. (2007). The Hedgehog-binding proteins Gas1 and Cdo cooperate to positively regulate Shh signaling during mouse development. Genes Dev. 21, 1244-1257. doi: 10.1101/gad.1543607

Altmann, T., and Gennery, A. R. (2016). DNA ligase IV syndrome; a review. Orphanet J. Rare Dis. 11:137.

Aoto, K., Shikata, Y., Higashiyama, D., Shiota, K., and Motoyama, J. (2008). Fetal ethanol exposure activates protein kinase A and impairs Shh expression in prechordal mesendoderm cells in the pathogenesis of holoprosencephaly. Birth Defects Res. A Clin. Mol. Teratol. 82, 224-231. doi: 10.1002/bdra.20447

Assenmacher, N., and Hopfner, K. P. (2004). MRE11/RAD50/NBS1: complex activities. Chromosoma 113, 157-166.

Bae, C. J., and Saint-Jeannet, J. P. (2014). “Induction and specification of neural crest cells: extracellular signals and transcriptional switches," in Neural Crest Cells: Evolution, Development and Disease, ed. P. Trainor (Amsterdam: Elsevier Inc), 27-49. doi: 10.1016/b978-0-12-401730-6.00002-8

Bae, G. U., Domené, S., Roessler, E., Schachter, K., Kang, J. S., Muenke, M., et al. (2011). Mutations in CDON, encoding a hedgehog receptor, result in holoprosencephaly and defective interactions with other hedgehog receptors. Am. J. Hum. Genet. 89, 231-240. doi: 10.1016/j.ajhg.2011. 07.001

Baggiolini, A., Varum, S., Mateos, J. M., Bettosini, D., John, N., Bonalli, M., et al. (2015). Premigratory and migratory neural crest cells are multipotent in vivo. Cell Stem Cell 16, 314-322. doi: 10.1016/j.stem.2015.02.017

Baroffio, A., Dupin, E., and Le Douarin, N. M. (1991). Common precursors for neural and mesectodermal derivatives in the cephalic neural crest. Development 112, 301-305.

Barriga, E. H., Trainor, P. A., Bronner, M., and Mayor, R. (2015). Animal models for studying neural crest development: is the mouse different? Development 142 , 1555-1560. doi: 10.1242/dev.121590

Bartholin, L., Powers, S. E., Melhuish, T. A., Lasse, S., Weinstein, M., and Wotton, D. (2006). TGIF inhibits retinoid signaling. Mol. Cell. Biol. 26, 990-1001. doi: 10.1128/mcb.26.3.990-1001.2006

Bartzela, T. N., Carels, C., and Maltha, J. C. (2017). Update on 13 syndromes affecting craniofacial and dental structures. Front. Physiol. 8:1038. doi: 10.3389/ fphys.2017.01038

Basch, M. L., Bronner-Fraser, M., and García-Castro, M. I. (2006). Specification of the neural crest occurs during gastrulation and requires Pax7. Nature 441, 218-222. doi: 10.1038/nature04684

Becerra, J. E., Khoury, M. J., Cordero, J. F., and Erickson, J. D. (1990). Diabetes mellitus during pregnancy and the risks for the specific birth defects: a population-based case-control study. Pediatrics 85 , 1-9.

\section{FUNDING}

Research in the Trainor Laboratory is supported by the Stowers Institute for Medical Research.

\section{ACKNOWLEDGMENTS}

We would like to thank Mark Miller for his help in illustrating Figures 1, 3, and 4 .

Bhatt, S., Diaz, R., and Trainor, P. A. (2013). Signals and switches in mammalian neural crest cell differentiation. Cold Spring Harb. Perspect. Biol. 5:a008326. doi: $10.1101 /$ cshperspect.a008326

Bhattacharya, D., Azambuja, A. P., and Simoes-Costa, M. (2020). Metabolic reprogramming promotes neural crest migration via Yap/Tead signaling. Dev. Cell 53, 199-211.e6.

Billington, C. J., Ng, B., Forsman, C., Schmidt, B., Bagchi, A., Symer, D. E., et al. (2011). The molecular and cellular basis of variable craniofacial phenotypes and their genetic rescue in twisted gastrulation mutant mice. Dev. Biol. 355, 21-31. doi: 10.1016/j.ydbio.2011.04.026

Boone, A. T. S., Chinn, I. K., Alaez-Versón, C., Yamazaki-Nakashimada, M. A., Carrillo-Sánchez, K., García-Cruz, M. L. H., et al. (2019). Failing to make ends meet: the broad clinical spectrum of DNA ligase IV deficiency. case series and review of the literature. Front. Pediatr. 6:426. doi: 10.3389/fped.2018.00426

Bronner, M. E., and LeDouarin, N. M. (2012). Development and evolution of the neural crest: an overview. Dev. Biol. 366, 2-9. doi: 10.1016/j.ydbio.2011.12.042

Brugmann, S. A., Allen, N. C., James, A. W., Mekonnen, Z., Madan, E., and Helms, J. A. (2010). A primary cilia-dependent etiology for midline facial disorders. Hum. Mol. Genet. 19, 1577-1592. doi: 10.1093/hmg/ddq030

Burke, R., Nellen, D., Bellotto, M., Hafen, E., Senti, K. A., Dickson, B. J., et al. (1999). Dispatched, a novel sterol-sensing domain protein dedicated to the release of cholesterol-modified hedgehog from signaling cells. Cell 99, 803-815. doi: 10.1016/s0092-8674(00)81677-3

Cano, A., Pérez-Moreno, M. A., Rodrigo, I., Locascio, A., Blanco, M. J., Del Barrio, M. G., et al. (2000). The transcription factor snail controls epithelialmesenchymal transitions by repressing E-cadherin expression. Nat. Cell Biol. 2, 76-83. doi: $10.1038 / 35000025$

Cao, S., Shen, W. B., Reece, E. A., and Yang, P. (2020). Deficiency of the oxidative stress-responsive kinase p70S6K1 restores autophagy and ameliorates neural tube defects in diabetic embryopathy. Am. J. Obstet. Gynecol. 223, 753.e1753.e14.

Carey, J. C. (1992). Syndromes of the head and neck. Robert J. Gorlin, M. Michael Cohen Jr., and L. Stefan Levin.New York: Oxford University Press, 1990, 977 pp. Am. J. Med. Genet. 42:144. doi: 10.1002/ajmg.1320420133

Casson, I. F., Clarke, C. A., Howard, C. V., McKendrick, O., Pennycook, S., Pharoah, P. O. D., et al. (1997). Outcomes of pregnancy in insulin dependent diabetic women: results of a five year population cohort study. $\mathrm{Br}$. Med. J. 315, 275-278. doi: 10.1136/bmj.315.7103.275

Castilla-Peon, M. F., Medina Bravo, P. G., Sánchez-Urbina, R., Gallardo-Montoya, J. M., Soriano-López, L. C., and Coronel Cruz, F. M. (2019). Diabetes and obesity during pregnancy are associated with oxidative stress genotoxicity in newborns. J. Perinatal Med. 47, 347-353. doi: 10.1515/jpm-2018-0201

Chai, Y., Jiang, X., Ito, Y., Bringas, P., Han, J., Rowitch, D. H., et al. (2000). Fate of the mammalian cranial neural crest during tooth and mandibular morphogenesis. Development 127, 1671-1679.

Chappell, J. H., Wang, X. D., and Loeken, M. R. (2009). Diabetes and apoptosis: neural crest cells and neural tube. Apoptosis 14, 1472-1483. doi: 10.1007/ s10495-009-0338-6

Chen, S. Y., and Sulik, K. K. (1996). Free radicals and ethanol-induced cytotoxicity in neural crest cells. Alcohol. Clin. Exp. Res. 20, 1071-1076. doi: 10.1111/j.15300277.1996.tb01948.x

Chiang, C., Litingtung, Y., Lee, E., Young, K. E., Corden, J. L., Westphal, H., et al. (1996). Cyclopia and defective axial patterning in mice lacking Sonic hedgehog gene function. Nature 383, 407-413. doi: 10.1038/383407a0 
Chrzanowska, K. H., Gregorek, H., Dembowska-Baginska, B., Kalina, M. A., and Digweed, M. (2012). Nijmegen breakage syndrome (NBS). Orphanet J. Rare Dis. $7: 13$.

Chrzanowska, K. H., Stumm, M., Bekiesiska-Figatowska, M., Varon, R., Biaecka, M., Gregorek, H., et al. (2001). Atypical clinical picture of the Nijmegen breakage syndrome associated with developmental abnormalities of the brain. J. Med. Genet. 38:E3.

Ciccia, A., Huang, J. W., Izhar, L., Sowa, M. E., Harper, J. W., and Elledge, S. J. (2014). Treacher Collins syndrome TCOF1 protein cooperates with NBS1 in the DNA damage response. Proc. Natl. Acad. Sci.U.S.A. 111, 18631-18636. doi: $10.1073 /$ pnas.1422488112

Cohen, M. M. (2006). Holoprosencephaly: clinical, anatomic, and molecular dimensions. Birth Defects Res. A Clin. Mol. Teratol. 76, 658-673. doi: 10.1002/ bdra. 20295

Coles, E. G., Taneyhill, L. A., and Bronner-Fraser, M. (2007). A critical role for Cadherin6B in regulating avian neural crest emigration. Dev. Biol. 312, 533-544. doi: 10.1016/j.ydbio.2007.09.056

Cordero, D., Marcucio, R., Hu, D., Gaffield, W., Tapadia, M., and Helms, J. A. (2004). Temporal perturbations in sonic hedgehog signaling elicit the spectrum of holoprosencephaly phenotypes. J. Clin. Investig. 114, 485-494. doi: 10.1172/ jci200419596

Crane, J. F., and Trainor, P. A. (2006). Neural crest stem and progenitor cells. Annu. Rev. Cell Dev. Biol. 22, 267-286.

Dash, S., and Trainor, P. A. (2020). The development, patterning and evolution of neural crest cell differentiation into cartilage and bone. Bone 137:115409. doi: 10.1016/j.bone.2020.115409

Dauwerse, J. G., Dixon, J., Seland, S., Ruivenkamp, C. A. L., Van Haeringen, A., Hoefsloot, L. H., et al. (2011). Mutations in genes encoding subunits of RNA polymerases i and III cause treacher collins syndrome. Nat. Genet. 43, 20-22. doi: $10.1038 /$ ng.724

Davis, W. L., Crawford, L. A., Cooper, O. J., Farmer, G. R., Thomas, D. L., and Freeman, B. L. (1990). Ethanol induces the generation of reactive free radicals by neural crest cells in vitro. J. Craniofac. Genet. Dev. Biol. 10, 277-293.

Denef, N., Neubüser, D., Perez, L., and Cohen, S. M. (2000). Hedgehog induces opposite changes in turnover and subcellular localization of patched and smoothened. Cell 102, 521-531. doi: 10.1016/s0092-8674(00)00056-8

Dixon, J., and Dixon, M. J. (2004). Genetic Background has a major effect on the penetrance and severity of craniofacial defects in mice heterozygous for the gene encoding the nucleolar protein treacle. Dev. Dyn. 229, 907-914. doi: 10.1002/dvdy. 20004

Dixon, J., Edwards, S. J., Gladwin, A. J., Dixon, M. J., Loftus, S. K., Bonner, C. A., et al. (1996). Positional cloning of a gene involved in the pathogenesis of treacher collins syndrome. Nat. Genet. 12, 130-136. doi: 10.1038/ng0296-130

Dixon, J., Jones, N. C., Sandell, L. L., Jayasinghe, S. M., Crane, J., Rey, J. P., et al. (2006). Tcof1/Treacle is required for neural crest cell formation and proliferation deficiencies that cause craniofacial abnormalities. Proc. Natl. Acad. Sci.U.S.A. 103, 13403-13408. doi: 10.1073/pnas.0603730103

Dixon, M. J., Marres, H. A. M., Edwards, S. J., Dixon, J., and Cremers, C. W. R. J. (1994). Treacher collins syndrome: correlation between clinical and genetic linkage studies. Clin. Dysmorphol. 3, 96-103.

Dong, D., Yu, J., Wu, Y., Fu, N., Villela, N. A., and Yang, P. (2015). Maternal diabetes triggers DNA damage and DNA damage response in neurulation stage embryos through oxidative stress. Biochem. Biophys. Res. Commun. 467, 407-412. doi: 10.1016/j.bbrc.2015.09.137

Duan, X., Kelsen, S. G., Clarkson, A. B., Ji, R., and Merali, S. (2010). SILAC analysis of oxidative stress-mediated proteins in human pneumocytes: new role for treacle. Proteomics 10, 2165-2174. doi: 10.1002/pmic. 201000020

Dupin, E., Calloni, G. W., and Le Douarin, N. M. (2010). The cephalic neural crest of amniote vertebrates is composed of a large majority of precursors endowed with neural, melanocytic, chondrogenic and osteogenic potentialities. Cell Cycle 9, 238-249. doi: 10.4161/cc.9.2.10491

Edwards, S. J., Fowlie, A., Cust, M. P., Liu, D. T., Young, I. D., and Dixon, M. J. (1996). Prenatal diagnosis in treacher collins syndrome using combined linkage analysis and ultrasound imaging. J. Med. Genet. 33, 603-606. doi: 10.1136/jmg. 33.7.603

Edwards, S. J., Gladwin, A. J., and Dixon, M. J. (1997). The mutational spectrum in treacher collins syndrome reveals a predominance of mutations that create a premature-termination codon. Am. J. Hum. Genet. 60, 515-524.
El-hage, S., and Singh, S. M. (1990). Temporal expression of genes encoding free radical-metabolizing enzymes is associated with higher mRNA levels during in utero development in mice. Dev. Genet. 11, 149-159. doi: 10.1002/dvg. 1020110205

Ericson, J., Muhr, J., Jessell, T. M., and Edlund, T. (1995). Sonic hedgehog: a common signal for ventral patterning along the rostrocaudal axis of the neural tube. Int. J. Dev. Biol. 39, 809-816.

Ewart-Toland, A., Yankowitz, J., Winder, A., Imagire, R., Cox, V. A., Aylsworth, A. S., et al. (2000). Oculoauriculovertebral abnormalities in children of diabetic mothers. Am. J. Med. Genet. 90, 303-309. doi: 10.1002/(sici)10968628(20000214)90:4<303::aid-ajmg8>3.0.co;2-q

Fernet, M., Gribaa, M., Salih, M. A. M., Seidahmed, M. Z., Hall, J., and Koenig, M. (2005). Identification and functional consequences of a novel MRE11 mutation affecting 10 Saudi Arabian patients with the ataxia telangiectasia-like disorder. Hum. Mol. Genet. 14, 307-318. doi: 10.1093/hmg/ddi027

Fetita, L. S., Sobngwi, E., Serradas, P., Calvo, F., and Gautier, J. F. (2006). Consequences of fetal exposure to maternal diabetes in offspring. J. Clin. Endocrinol. Metab. 91, 3718-3724. doi: 10.1210/jc.2006-0624

Frappart, P. O., Tong, W. M., Demuth, I., Radovanovic, I., Herceg, Z., Aguzzi, A., et al. (2005). An essential function for NBS1 in the prevention of ataxia and cerebellar defects. Nat. Med. 11, 538-544. doi: $10.1038 / \mathrm{nm} 1228$

Gans, C., and Northcutt, R. G. (1983). Neural crest and the origin of vertebrates: a new head. Science 220, 268-273. doi: 10.1126/science.220. 4594.268

García-Castro, M. I., Marcelle, C., and Bronner-Fraser, M. (2002). Ectodermal Wnt function as a neural crest inducer. Science 297, 848-851.

Gelaleti, R. B., Damasceno, D. C., Salvadori, D. M. F., Marcondes, J. P. C., Lima, P. H. O., Morceli, G., et al. (2015). IRS-1 gene polymorphism and DNA damage in pregnant women with diabetes or mild gestational hyperglycemia. Diabetol. Metab. Syndr. 7:30.

Geng, X., and Oliver, G. (2009). Pathogenesis of holoprosencephaly. J. Clin. Invest. 119, 1403-1413. doi: 10.1172/jci38937

Ghesh, L., Vincent, M., Delemazure, A., Boyer, J., Corre, P., Perez, F., et al. (2019). Autosomal recessive treacher collins syndrome due to POLR1C mutations: report of a new family and review of the literature. Am. J. Med. Genet. A 179, 1390-1394.

Golden, J. A. (1999). Towards a greater understanding of the pathogenesis of holoprosencephaly. Brain Dev. 21, 513-521. doi: 10.1016/s0387-7604(99) 00067-4

Gongal, P. A., and Waskiewicz, A. J. (2008). Zebrafish model of holoprosencephaly demonstrates a key role for TGIF in regulating retinoic acid metabolism. Hum. Mol. Genet. 17, 525-538. doi: 10.1093/hmg/ddm328

Goodrich, L. V., Jung, D., Higgins, K. M., and Scott, M. P. (1999). Overexpression of ptc1 inhibits induction of Shh target genes and prevents normal patterning in the neural tube. Dev. Biol. 211, 323-334. doi: 10.1006/dbio.1999.9311

Gorlin, R. J., Cohen, M. M. Jr., and Hennekam, R. C. M. (1990). Syndromes of the Head and Neck. Oxford: Oxford University Press.

Gowen, L. C., Johnson, B. L., Latour, A. M., Sulik, K. K., and Koller, B. H. (1996). Brcal deficiency results in early embryonic lethality characterized by neuroepithelial abnormalities. Nat. Genet. 12, 191-194. doi: 10.1038/ng0296191

Greene, M. F. (2001). Diabetic embryopathy 2001: moving beyond the'diabetic milieu'. Teratology 63, 116-118.

Grinblat, Y., and Lipinski, R. J. (2019). A forebrain undivided: unleashing model organisms to solve the mysteries of holoprosencephaly. Dev. Dyn. 248, 626-633. doi: $10.1002 /$ dvdy.41

Guerrero, I., and Chiang, C. (2007). A conserved mechanism of hedgehog gradient formation by lipid modifications. Trends Cell Biol. 17, 1-5. doi: 10.1016/j.tcb. 2006.11.002

Hahn, J. S., Barnes, P. D., Clegg, N. J., and Stashinko, E. E. (2010). Septopreoptic holoprosencephaly: a mild subtype associated with midline craniofacial anomalies. Am. J. Neuroradiol. 31, 1596-1601. doi: 10.3174/ajnr.a2123

Hahn, J. S., and Barnes, P. D. (2010). Neuroimaging advances in holoprosencephaly: refining the spectrum of the midline malformation. Am. J. Med. Genet. Pt. C Semin. Med. Genet. 154C, 120-132. doi: 10.1002/ajmg.c.30238

Hakem, R., De La Pompa, J. L., Sirard, C., Mo, R., Woo, M., Hakem, A., et al. (1996). The tumor suppressor gene Brcal is required for embryonic cellular 
proliferation in the mouse. Cell 85, 1009-1023. doi: 10.1016/s0092-8674(00) 81302-1

Hall, B. K. (1999). The Neural Crest in Development and Evolution. New York, NY: Springer Science.

Hammerschmidt, M., Bitgood, M. J., and McMahon, A. P. (1996). Protein kinase A is a common negative regulator of Hedgehog signaling in the vertebrate embryo. Genes Dev. 10, 647-658. doi: 10.1101/gad.10.6.647

Han, D., Schomacher, L., Schüle, K. M., Mallick, M., Musheev, M. U., Karaulanov, E., et al. (2019). NEIL1 and NEIL2 DNA glycosylases protect neural crest development against mitochondrial oxidative stress. ELife 8:e49044.

Hatta, K., and Takeichi, M. (1986). Expression of N-cadherin adhesion molecules associated with early morphogenetic events in chick development. Nature 320 , 447-449. doi: 10.1038/320447a0

Hawthorne, G., Robson, S., Ryall, E. A., Sen, D., Roberts, S. H., and Ward Platt, M. P. (1997). Prospective population based survey of outcome of pregnancy in diabetic women: results of the northern diabetic pregnancy audit, 1994. Br. Med. J. 315, 279-281. doi: 10.1136/bmj.315.7103.279

Hong, M., and Krauss, R. S. (2017). Ethanol itself is a holoprosencephaly-inducing teratogen. PLoS One 12:e0176440. doi: 10.1371/journal.pone.0176440

Hong, S., Hu, P., Roessler, E., Hu, T., and Muenke, M. (2018). Loss-of-function mutations in FGF8 can be independent risk factors for holoprosencephaly. Hum. Mol. Genet. 27, 1989-1998. doi: 10.1093/hmg/ddy106

Jones, D. P., and Sies, H. (2015). The redox code. Antioxid. Redox Signal. 23, 734-746. doi: 10.1089/ars.2015.6247

Jones, K. L., Smith, D. W., Harvey, M. A. S., Hall, B. D., and Quan, L. (1975). Older paternal age and fresh gene mutation: data on additional disorders. J. Pediatr. 86, 84-88. doi: 10.1016/s0022-3476(75)80709-8

Jones, N. C., Lynn, M. L., Gaudenz, K., Sakai, D., Aoto, K., Rey, J. P., et al. (2008). Prevention of the neurocristopathy treacher collins syndrome through inhibition of p53 function. Nat. Med. 14, 125-133. doi: 10.1038/ nm 1725

Kandilya, D., Shyamasundar, S., Singh, D. K., Banik, A., Hande, M. P., Stünkel, W., et al. (2020). High glucose alters the DNA methylation pattern of neurodevelopment associated genes in human neural progenitor cells in vitro. Sci. Rep. 10:15676.

Kemp, M., Go, Y. M., and Jones, D. P. (2008). Nonequilibrium thermodynamics of thiol/disulfide redox systems: a perspective on redox systems biology. Free Radic. Biol. Med. 44, 921-937. doi: 10.1016/j.freeradbiomed.2007.11.008

Kim, G., Cao, L., Reece, E. A., and Zhao, Z. (2017). Impact of protein O-GlcNAcylation on neural tube malformation in diabetic embryopathy. Sci. Rep. 7:11107.

Kitami, K., Kitami, M., Kaku, M., Wang, B., and Komatsu, Y. (2018). BRCA1 and BRCA2 tumor suppressors in neural crest cells are essential for craniofacial bone development. PLoS Genet. 14:e1007340. doi: 10.1371/journal.pgen. 1007340

Kobayashi, G. S., Alvizi, L., Sunaga, D. Y., Francis-West, P., Kuta, A., Almada, B. V. P., et al. (2013). Susceptibility to DNA damage as a molecular mechanism for non-syndromic cleft lip and palate. PLoS One 8:e65677. doi: 10.1371/journal. pone.0065677

Kobayashi, J., Antoccia, A., Tauchi, H., Matsuura, S., and Komatsu, K. (2004). NBS1 and its functional role in the DNA damage response. DNA Repair 3, 855-861. doi: 10.1016/j.dnarep.2004.03.023

Kruszka, P., and Muenke, M. (2018). Syndromes associated with holoprosencephaly. Am. J. Med. Genet. Semin. Med. Genet. 178, 229-237. doi: 10.1002/ajmg.c.31620

Kucera, J. (1971). Rate and type of congenital anomalies among offspring of diabetic women. J. Reprod. Med. 7, 73-82.

Kulesa, P. M., Bailey, C. M., Kasemeier-Kulesa, J. C., and McLennan, R. (2010). Cranial neural crest migration: new rules for an old road. Dev. Biol. 344, 543-554. doi: 10.1016/j.ydbio.2010.04.010

Larsen, D. H., Hari, F., Clapperton, J. A., Gwerder, M., Gutsche, K., Altmeyer, M., et al. (2014). The NBS1-treacle complex controls ribosomal RNA transcription in response to DNA damage. Nat. Cell Biol. 16, 792-803. doi: 10.1038/ncb3007

Le Douarin, N. M., Creuzet, S., Couly, G., and Dupin, E. (2004). Neural crest cell plasticity and its limits. Development 131, 4637-4650. doi: 10.1242/dev.01350

Le Douarin, N., and Kalcheim, C. (1999). The Neural Crest. Cambridge: Cambridge University Press.
Lepage, T., Cohen, S. M., Diaz-Benjumea, F. J., and Parkhurst, S. M. (1995). Signal transduction by cAMP-dependent protein kinase A in Drosophila limb patterning. Nature 373, 711-715. doi: 10.1038/373711a0

Li, R., Chase, M., Jung, S.-K., Smith, P. J. S., and Loeken, M. R. (2005). Hypoxic stress in diabetic pregnancy contributes to impaired embryo gene expression and defective development by inducing oxidative stress. Am. J. Physiol. Endocrinol. Metab. 289, 591-599.

Liao, D. M., Ng, Y. K., Tay, S. S. W., Ling, E. A., and Dheen, S. T. (2004). Altered gene expression with abnormal patterning of the telencephalon in embryos of diabetic albino swiss mice. Diabetologia 47, 523-531. doi: 10.1007/s00125-0041351-5

Liu, C. Y., Flesken-Nikitin, A., Li, S., Zeng, Y., and Lee, W. H. (1996). Inactivation of the mouse Brcal gene leads to failure in the morphogenesis of the egg cylinder in early postimplantation development. Genes Dev. 10, 1835-1843. doi: $10.1101 /$ gad.10.14.1835

Loeken, M. R. (2006). Advances in understanding the molecular causes of diabetesinduced birth defects. J. Soc. Gynecol. Investig. 13, 2-10. doi: 10.1016/j.jsgi.2005. 09.007

Loeken, M. R. (2020). Mechanisms of congenital malformations in pregnancies with pre-existing diabetes. Curr. Diab. Rep. 20:54.

Marres, H. A. M., Cremers, W. R. J., Dixon, M. J., Huygen, P. L. M., and Joosten, F. B. M. (1995). The treacher collins syndrome: a clinical, radiological, and genetic linkage study on two pedigrees. Arch. Otolaryngol. Head Neck Surg. 121, 509-514. doi: 10.1001/archotol.1995.01890050009002

Matsumoto, Y., Miyamoto, T., Sakamoto, H., Izumi, H., Nakazawa, Y., Ogi, T., et al. (2011). Two unrelated patients with MRE11A mutations and Nijmegen breakage syndrome-like severe microcephaly. DNA Repair 10, 314-321. doi: 10.1016/j.dnarep.2010.12.002

Mayor, R., and Theveneau, E. (2012). The neural crest. Development 140, $2247-$ 2251.

McKinnon, P. J. (2012). ATM and the molecular pathogenesis of ataxia telangiectasia. Annu. Rev. Pathol. 7, 303-321. doi: 10.1146/annurev-pathol011811-132509

Mille, F., Tamayo-Orrego, L., Lévesque, M., Remke, M., Korshunov, A., Cardin J., et al. (2014). The Shh receptor Boc promotes progression of early medulloblastoma to advanced tumors. Dev. Cell 31, 34-47. doi: 10.1016/j. devcel.2014.08.010

Mills, J. L. (2010). Malformations in infants of diabetic mothers. teratology 25:38594. 1982. Birth Defects Res. A Clin. Mol. Teratol. 88, 769-778. doi: 10.1002/bdra. 20757

Mills, J. L., Baker, L., and Goldman, A. S. (1979). Malformations in infants of diabetic mothers occur before the seventh gestational week. Implications for treatment. Diabetes 28, 292-293. doi: 10.2337/diabetes.28.4.292

Morrison, J. A., McLennan, R., Wolfe, L. A., Gogol, M. M., Meier, S., McKinney, M. C., et al. (2017). Single-cell transcriptome analysis of avian neural crest migration reveals signatures of invasion and molecular transitions. ELife 6:e28415.

Mullor, J. L., and Guerrero, I. (2000). A gain-of-function mutant of patched dissects different responses to the Hedgehog gradient. Dev. Biol. 228, 211-224. doi: 10.1006/dbio.2000.9862

Nieto, M. A., Sargent, M. G., Wilkinson, D. G., and Cooke, J. (1994). Control of cell behavior during vertebrate development by Slug, a zinc finger gene. Science 264, 835-839. doi: 10.1126/science.7513443

Noack Watt, K. E., Achilleos, A., Neben, C. L., Merrill, A. E., and Trainor, P. A. (2016). The roles of RNA polymerase I and III subunits Polr1c and Polr1d in craniofacial development and in zebrafish models of treacher collins syndrome. PLoS Genet. 12:e1006187. 10.1371/journal.pgen.10 06187

Noden, D. M. (1983). The role of the neural crest in patterning of avian cranial skeletal, connective, and muscle tissues. Dev. Biol. 96, 144-165. doi: 10.1016/ 0012-1606(83)90318-4

Noden, D. M., and Trainor, P. A. (2005). Relations and interactions between cranial mesoderm and neural crest populations. J. Anat. 207, 575-601. doi: 10.1111/j.1469-7580.2005.00473.x

Ornoy, A. (2007). Embryonic oxidative stress as a mechanism of teratogenesis with special emphasis on diabetic embryopathy. Reprod. Toxicol. 24, 31-41. doi: 10.1016/j.reprotox.2007.04.004 
Osumi-Yamashita, N., Ninomiya, Y., Doi, H., and Eto, K. (1994). The contribution of both forebrain and midbrain crest cells to the mesenchyme in the frontonasal mass of mouse embryos. Dev. Biol. 164, 409-419. doi: 10.1006/dbio.1994.1211

Pan, D., and Rubin, G. M. (1995). cAMP-dependent protein kinase and hedgehog act antagonistically in regulating decapentaplegic transcription in drosophila imaginal discs. Cell 80, 543-552. doi: 10.1016/0092-8674(95)90508-1

Pani, L., Horal, M., and Loeken, M. R. (2002). Rescue of neural tube defects in Pax3-deficient embryos by 53 loss of function: implications for Pax-3-dependent development and tumorigenesis. Genes Dev. 16, 676-680. doi: 10.1101/gad. 969302

Paull, T. T., and Lee, J. H. (2005). The Mre11/Rad50/Nbs1 complex and its role as a DNA double-strand break sensor for ATM. Cell Cycle 4, 737-740. doi: 10.4161/cc.4.6.1715

Pavlinkova, G., Michael, J. M., and Kappen, C. (2009). Maternal diabetes alters transcriptional programs in the developing embryo. BMC Genomics 10:274. doi: 10.1186/1471-2164-10-274

Petryk, A., Graf, D., and Marcucio, R. (2015). Holoprosencephaly: signaling interactions between the brain and the face, the environment and the genes, and the phenotypic variability in animal models and humans. Wiley Interdiscip. Rev. Dev. Biol. 4, 17-32. doi: 10.1002/wdev.161

Phelan, S. A., Ito, M., and Loeken, M. R. (1997). Neural tube defects in embryos of diabetic mice: role of the Pax-3 gene and apoptosis. Diabetes 46, 1189-1197. doi: 10.2337/diabetes.46.7.1189

Porter, F. D., and Herman, G. E. (2011). Malformation syndromes caused by disorders of cholesterol synthesis. J. Lipid Res. 52, 6-34. doi: 10.1194/jlr.r009548

Poswillo, D. (1975). Causal mechanisms of craniofacial deformity. Br. Med. Bull. 31, 101-106. doi: 10.1093/oxfordjournals.bmb.a071260

Prasad, M. S., Uribe-Querol, E., Marquez, J., Vadasz, S., Yardley, N., Shelar, P. B., et al. (2020). Blastula stage specification of avian neural crest. Dev. Biol. 458, 64-74. doi: 10.1016/j.ydbio.2019.10.007

Ramya, S., Shyamasundar, S., Bay, B. H., and Dheen, S. T. (2017). Maternal diabetes alters expression of MicroRNAs that regulate genes critical for neural tube development. Front. Mol. Neurosci. 10:237. doi: 10.3389/fnmol.2017.00237

Richards, M. J., Nagel, B. A., and Fliesler, S. J. (2006). Lipid hydroperoxide formation in the retina: correlation with retinal degeneration and light damage in a rat model of Smith-Lemli-Opitz syndrome. Exp. Eye Res. 82, 538-541. doi: 10.1016/j.exer.2005.08.016

Richbourg, H. A., Hu, D. P., Xu, Y., Barczak, A. J., and Marcucio, R. S. (2020). miR-199 family contributes to regulation of sonic hedgehog expression during craniofacial development. Dev. Dyn. 249, 1062-1076. doi: 10.1002/dvdy.191

Roessler, E., Belloni, E., Gaudenz, K., Jay, P., Berta, P., Scherer, S. W., et al. (1996). Mutations in the human sonic hedgehog gene cause holoprosencephaly. Nat. Genet. 14, 357-360. doi: 10.1038/ng1196-357

Roessler, E., Du, Y. Z., Mullor, J. L., Casas, E., Allen, W. P., Gillessen-Kaesbach, G., et al. (2003). Loss-of-function mutations in the human GLI2 gene are associated with pituitary anomalies and holoprosencephaly-like features. Proc. Natl. Acad. Sci.U.S.A. 100, 13424-13429. doi: 10.1073/pnas.2235734100

Roessler, E., Hu, P., Marino, J., Hong, S., Hart, R., Berger, S., et al. (2018). Common genetic causes of holoprosencephaly are limited to a small set of evolutionarily conserved driver genes of midline development coordinated by TGF- $\beta$, hedgehog, and FGF signaling. Hum. Mutat. 39, 1416-1427. doi: 10. 1002/humu. 23590

Roessler, E., Lacbawan, F., Dubourg, C., Paulussen, A., Herbergs, J., Hehr, U., et al. (2009). The full spectrum of holoprosencephaly-associated mutations within the ZIC2 gene in humans predicts loss-of-function as the predominant disease mechanism. Hum. Mutat. 30, E541-E554.

Rubbi, C. P., and Milner, J. (2003). Disruption of the nucleolus mediates stabilization of p53 in response to DNA damage and other stresses. EMBO J. 22, 6068-6077. doi: 10.1093/emboj/cdg579

Ruiz, I., and Altaba, A. (1999). Gli proteins and hedgehog signaling: development and cancer. Trends Genet. 15, 418-425. doi: 10.1016/s0168-9525(99)01840-5

Sakai, D., and Trainor, P. A. (2016). Face off against ROS: Tcof1/Treacle safeguards neuroepithelial cells and progenitor neural crest cells from oxidative stress during craniofacial development. Dev. Growth Differ. 58, 577-585. doi: 10. 1111/dgd.12305

Sakai, D., Dixon, J., Achilleos, A., Dixon, M., and Trainor, P. A. (2016). Prevention of treacher collins syndrome craniofacial anomalies in mouse models via maternal antioxidant supplementation. Nat. Commun. 7:10328.
Salbaum, J. M., and Kappen, C. (2010). Neural tube defect genes and maternal diabetes during pregnancy. Birth Defects Res. A Clin. Mol. Teratol. 88, 601-611. doi: 10.1002/bdra.20680

Sanchez, E., Laplace-Builhé, B., Mau-Them, F. T., Richard, E., Goldenberg, A., Toler, T. L., et al. (2020). POLR1B and neural crest cell anomalies in treacher collins syndrome type 4. Genet. Med. 22, 547-556. doi: 10.1038/s41436-0190669-9

Schneider, R. A., and Helms, J. A. (2003). The cellular and molecular origins of beak morphology. Science 299, 565-568. doi: 10.1126/science.1077827

Schneider, T., Bizarro, L., Asherson, P. J. E., and Stolerman, I. P. (2010). Gestational exposure to nicotine in drinking water: teratogenic effects and methodological issues. Behav. Pharmacol. 21, 206-216. doi: 10.1097/fbp.0b013e32833a5bb5

Seeman, P., Gebertová, K., Paděrová, K., Sperling, K., and Seemanová, E. (2004). Nijmegen breakage syndrome in $13 \%$ of age-matched Czech children with primary microcephaly. Pediatric Neurol. 30, 195-200. doi: 10.1016/j. pediatrneurol.2003.07.003

Shang, Z., Chen, D., Wang, Q., Wang, S., Deng, Q., Wu, L., et al. (2018). Singlecell RNA-seq reveals dynamic transcriptome profiling in human early neural differentiation. GigaScience 7:giy117.

Shyamasundar, S., Jadhav, S. P., Bay, B. H., Tay, S. S. W., Kumar, S. D., Rangasamy, D., et al. (2013). Analysis of epigenetic factors in mouse embryonic neural stem cells exposed to hyperglycemia. PLoS One 8:e65945. doi: 10.1371/journal.pone. 0065945

Simões-Costa, M., and Bronner, M. E. (2015). Establishing neural crest identity: a gene regulatory recipe. Development 142, 242-257. doi: 10.1242/dev.105445

Soldatov, R., Kaucka, M., Kastriti, M. E., Petersen, J., Chontorotzea, T., Englmaier, L., et al. (2019). Spatiotemporal structure of cell fate decisions in murine neural crest. Science 364, 971-984.

Solomon, B. D., Lacbawan, F., Jain, M., Domene, S., Roessler, E., Moore, C., et al. (2009). A novel six3 mutation segregates with holoprosencephaly in a large family. Am. J. Med. Genet. A 149, 919-925. doi: 10.1002/ajmg.a.32813

Solomon, B. D., Mercier, S., Vélez, J. I., Pineda-Alvarez, D. E., Wyllie, A., Zhou, N., et al. (2010). Analysis of genotype-phenotype correlations in human holoprosencephaly. Am. J. Med. Genet. C Semin. Med. Genet. 154C, 133-141. doi: 10.1002/ajmg.c.30240

Stracker, T. H., and Petrini, J. H. J. (2011). The MRE11 complex: starting from the ends. Nat. Rev. Mol. Cell Biol. 12, 90-103. doi: 10.1038/nrm3047

Sulik, K. K., Cook, C. S., and Webster, W. S. (1988). Teratogens and craniofacial malformations: relationships to cell death. Development 103, 213-232.

Tam, P. P. L., and Trainor, P. A. (1994). Specification and segmentation of the paraxial mesoderm. Anat. Embryol. 189, 275-305.

Taneyhill, L. A., and Padmanabhan, R. (2014). "The cell biology of neural crest cell delamination and EMT," in Neural Crest Cells: Evolution, Development and Disease, ed. P. Trainor (Amsterdam: Elsevier Inc), 51-72. doi: 10.1016/b978-012-401730-6.00003-x

Taniguchi, K., Anderson, A. E., Sutherland, A. E., and Wotton, D. (2012). Loss of tgif function causes holoprosencephaly by disrupting the Shh signaling pathway. PLoS Genet. 8:e1002524. doi: 10.1371/journal.pgen.1002524

Tenzen, T., Allen, B. L., Cole, F., Kang, J. S., Krauss, R. S., and McMahon, A. P. (2006). The cell surface membrane proteins Cdo and Boc are components and targets of the hedgehog signaling pathway and feedback network in mice. Dev. Cell 10, 647-656. doi: 10.1016/j.devcel.2006.04.004

Towner, D., Kjos, S. L., Leung, B., Montoro, M. M., Xiang, A., Mestman, J. H., et al. (1995). Congenital malformations in pregnancies complicated by NIDDM: increased risk from poor maternal metabolic control but not from exposure to sulfonylurea drugs. Diab. Care 18, 1446-1451. doi: 10.2337/diacare.18.11. 1446

Trainor, P. A. (2003). Making headway: the roles of Hox genes and neural crest cells in craniofacial development. ScientificWorldJournal 3, 240-264. doi: 10.1100/ tsw.2003.11

Trainor, P. A. (2010). Craniofacial birth defects: the role of neural crest cells in the etiology and pathogenesis of Treacher Collins syndrome and the potential for prevention. Am. J. Med. Genet. A 152A, 2984-2994. doi: 10.1002/ajmg.a. 33454

Trainor, P. A. (2013). "Molecular blueprint for craniofacial morphogenesis and development," in Stem Cells in Craniofacial Development and Regeneration, eds I. Thesleff and G. T. J. Huang (Hoboken, NJ: John Wiley \& Sons, Inc), 1-29. doi: $10.1002 / 9781118498026 . c h 1$ 
Trainor, P. A., and Krumlauf, R. (2001). Hox genes, neural crest cells and branchial arch patterning. Curr. Opin. Cell Biol. 13, 698-705. doi: 10.1016/s09550674(00)00273-8

Trainor, P. A., and Krumlauf, R. (2002). Riding the crest of the Wnt signaling wave. Science 297, 781-783. doi: 10.1126/science.1075454

Trainor, P. A., and Tam, P. P. L. (1995). Cranial paraxial mesoderm and neural crest cells of the mouse embryo: co-distribution in the craniofacial mesenchyme but distinct segregation in branchial arches. Development 121, 2569-2582.

Trainor, P. A., Dixon, J., and Dixon, M. J. (2009). Treacher collins syndrome: etiology, pathogenesis and prevention. Eur. J. Hum. Genet. 17, 275-283. doi: 10.1038/ejhg.2008.221

Trainor, P. A., Melton, K. R., and Manzanares, M. (2003). Origins and plasticity of neural crest cells and their roles in jaw and craniofacial evolution. Int. J. Dev. Biol. 47, 541-553.

Trainor, P. A., Sobieszczuk, D., Wilkinson, D., and Krumlauf, R. (2002). Signalling between the hindbrain and paraxial tissues dictates neural crest migration pathways. Development 129, 433-442.

Twigg, S. R. F., and Wilkie, A. O. M. (2015). New insights into craniofacial malformations. Hum. Mol. Genet. 24, R50-R59.

Valdez, B. C., Henning, D., So, R. B., Dixon, J., and Dixon, M. J. (2004). The treacher collins syndrome (TCOF1) gene product is involved in ribosomal DNA gene transcription by interacting with upstream binding factor. Proc. Natl. Acad. Sci.U.S.A. 101, 10709-10714. doi: 10.1073/pnas.0402492101

Van De Putte, T., Maruhashi, M., Francis, A., Nelles, L., Kondoh, H., Huylebroeck, D., et al. (2003). Mice lacking Zfhxlb, the gene that codes for Smad-interacting protein-1, reveal a role for multiple neural crest cell defects in the etiology of hirschsprung disease-mental retardation syndrome. Am. J. Hum. Genet. 72, 465-470. doi: 10.1086/346092

Von Kries, R., Kimmerle, R., Schmidt, J. E., Hachmeister, A., Böhm, O., and Wolf, H. G. (1997). Pregnancy outcomes in mothers with pregestational diabetes: a population-based study in North Rhine (Germany) from 1988 to 1993. Eur. J. Pediatr. 156, 963-967. doi: 10.1007/s004310050752

Waltes, R., Kalb, R., Gatei, M., Kijas, A. W., Stumm, M., Sobeck, A., et al. (2009). Human RAD50 deficiency in a nijmegen breakage syndrome-like disorder. Am. J. Hum. Genet. 84, 605-616. doi: 10.1016/j.ajhg.2009.04.010

Wang, F., Xu, C., Reece, E. A., Li, X., Wu, Y., Harman, C., et al. (2017). Protein kinase C-alpha suppresses autophagy and induces neural tube defects via miR-129-2 in diabetic pregnancy. Nat. Commun. 8:15182.

Wang, X. Y., Li, S., Wang, G., Ma, Z. L., Chuai, M., Cao, L., et al. (2015). High glucose environment inhibits cranial neural crest survival by activating excessive autophagy in the chick embryo. Sci. Rep. 5:18321.

Warburg, O. (1956). On the origin of cancer cells. Science 123, 309-314.

Watt, K. E. N., and Trainor, P. A. (2014). "Neurocristopathies. the etiology and pathogenesis of disorders arising from defects in neural crest cell development," in Neural Crest Cells: Evolution, Development and Disease, ed. P. Trainor (Amsterdam: Elsevier Inc), 361-394. doi: 10.1016/b978-0-12-401730-6. 00018-1

Wei, D., and Loeken, M. R. (2014). Increased DNA methyltransferase 3b (dnmt3b)mediated $\mathrm{CpG}$ island methylation stimulated by oxidative stress inhibits expression of a gene required for neural tube and neural crest development in diabetic pregnancy. Diabetes 63, 3512-3522. doi: 10.2337/db14-0231

Wells, P. G., McCallum, G. P., Lam, K. C. H., Henderson, J. T., and Ondovcik, S. L. (2010). Oxidative DNA damage and repair in teratogenesis and neurodevelopmental deficits. Birth Defects Res. C Embryo Today 90, 103-109. doi: 10.1002/bdrc.20177

Wentzel, P., and Eriksson, U. J. (2011). Altered gene expression in rat cranial neural crest cells exposed to a teratogenic glucose concentration in vitro-paradoxical downregulation of antioxidative defense genes. Birth Defects Res. B Dev. Reprod. Toxicol. 92, 487-497. doi: 10.1002/bdrb.20321

Wilder, H. H. (1908). The morphology of cosmobia; speculations concerning the significnace of certain types of monsters. Am. J. Anat. 8, 355-440. doi: 10.1002/ aja.1000080113

Williams, A. L., and Bohnsack, B. L. (2019). What's retinoic acid got to do with it? Retinoic acid regulation of the neural crest in craniofacial and ocular development. Genesis 57:e23308. doi: 10.1002/dvg.23308

Wong, J. C. Y., Alon, N., Mckerlie, C., Huang, J. R., Meyn, M. S., and Buchwald, M. (2003). Targeted disruption of exons 1 to 6 of the fanconi anemia group A gene leads to growth retardation, strain-specific microphthalmia, meiotic defects and primordial germ cell hypoplasia. Hum. Mol. Genet. 12, 2063-2076. doi: $10.1093 / \mathrm{hmg} / \mathrm{ddg} 219$

Wu, Y., Viana, M., Thirumangalathu, S., and Loeken, M. R. (2012). AMP-activated protein kinase mediates effects of oxidative stress on embryo gene expression in a mouse model of diabetic embryopathy. Diabetologia 55, 245-254. doi: 10.1007/s00125-011-2326-y

Xu, C., Li, X., Wang, F., Weng, H., and Yang, P. (2013). Trehalose prevents neural tube defects by correcting maternal diabetes-suppressed autophagy and neurogenesis. Am. J. Physiol. Endocrinol. Metab. 305, E667-E678.

Yamaguchi, H., Kitami, K., Wu, X., He, L., Wang, J., Wang, B., et al. (2021). Alterations of DNA damage response causes cleft palate. Front. Physiol. 12:649492. doi: 10.3389/fphys.2021.649492

Zhao, Z., and Reece, E. A. (2005). Nicotine-induced embryonic malformations mediated by apoptosis from increasing intracellular calcium and oxidative stress. Birth Defects Res. B Dev. Reprod. Toxicol. 74, 383-391. doi: 10.1002/bdrb. 20052

Zhao, Z., and Reece, E. A. (2013). New concepts in diabetic embryopathy. Clin. Lab. Med. 33, 207-233. doi: 10.1016/j.cll.2013.03.017

Conflict of Interest: The authors declare that the research was conducted in the absence of any commercial or financial relationships that could be construed as a potential conflict of interest.

Copyright (C) 2021 Fitriasari and Trainor. This is an open-access article distributed under the terms of the Creative Commons Attribution License (CC BY). The use, distribution or reproduction in other forums is permitted, provided the original author(s) and the copyright owner(s) are credited and that the original publication in this journal is cited, in accordance with accepted academic practice. No use, distribution or reproduction is permitted which does not comply with these terms. 